\title{
المدارس الأساسية في محافظة

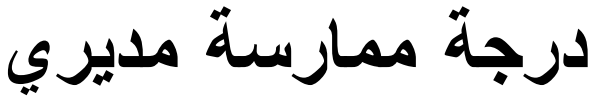 عجلون مهارة تحفيز المعلمين من وجهة نظر المعلمين
}

جملا صالح جروان إسماعيل البريد الاكتروني: Jamlaababneh@yahoo.com

الملخص

تعمل الدراسة الحالية على معرفة درجة ممارسة مديري المدارس الأساسية في محافظة عجلون لمهارة تحفيز المعلمين من وجهة نظر المعلمين، وعملت الباحثة على اتباع النهج الوصفي التحليلي، وتم تصميم استبيان، وتمثل مجتمع البحث بكافة المعلمات و المعلمين العاملين في المدارس الأساسية في محافظة عجلون في الاردن، وعملت الباحثة على توزيع الاستبيان الكترونيا الى 115 معلم ومعلمة من ثماني مدارس حكومية اساسية في عجلون، ولقد جرى اختيار هم عن طريقة الاسلوب القصدي، وتم استرجاع 103 استمارة صالحة للتحليل، وبلغت نسبة الاسترداد 59.56\%، وتم توظيف برنامج SPSS، وتبين ان درجة ممارسة مديري المدارس الأساسية في محافظة عجلون مهارة تحفيز المعلمين من وجهة نظر المعلمين نعد مرتفعة، ولقد تبين ان درجة قيام المدراء المستهدفين بإتاحة فرصاً للمعلمين لابداء ارائه وتزويد المعلمين بالتغذية الراجعة تعد مرتفعة، وتبين تبين ان درجة قيام المدراء المستهدفين باثر اك المعلمين في عملية اتخاذ القرار و تفويض الصلاحيات للمعلمين تعد مرتفعة، وتبين ان درجة قيام المدراء المستهدفين بمساعدة المعلمين في حل المشكلات تعد مرتفعة، وتبين ان درجة قيام المدراء المستهدفين بإرسال رسائل شكر للمعلمين المتميزين، وشكر المعلمين امام زملاءهم والثناء تعد مرتفعة. ولكن، تبين ان درجة قيام المدر اء المستهدفين بتقديم جو ائز مادية للمعلمين المنميزين تعد منخفضة، ولقد تبين ان درجة قيام المدر اء المستهدفين بتنظيم رحلات ترفيهية للمعلمين،تعد منخفضة، ودرجة قيام المدر اء بإقامة حفلات لتكريم للمعلمين المتميزين تعد منخفضة. الكلمات المفتاحية: التحفيز ، المدارس الاساسية، محافظة عجلون، مدارء المدارس، المعلمين. 
 Journal of Arts, Literature, Humanities and Social Sciences www.jalhss.com \\ The Extent of Practicing the Skill of Motivating Teachers by the Basic School Principals in Ajloun from the Teachers' Perspective
}

Jamla Saleh Jarwan Ismail

Email: Jamlaababneh@yahoo.com

\begin{abstract}
This research investigated the extent of practicing the skill of motivating teachers by the basic school principals in Ajloun from the teachers' perspective. The researcher adopted a descriptive analytical approach. A survey was designed. The population of this research involves all the female and male teachers working at the basic schools located in Ajloun, Jordan. The survey forms were passed online to 115 female and male teachers who were chosen from 8 basic schools in Ajloun. Those teachers were chosen purposively. 103 forms were retrieved. They were deemed valid for analysis. The response rate is $89.56 \%$. SPSS software was used. The researcher found that the extent of practicing the skill of motivating teachers by the basic school principals in Ajloun from the teachers' perspective is high. She found that the degree to which the targeted principals provide teachers with feedback and opportunities to express their views is high. The degree to which the targeted principals engage teachers in the decision making process and delegate powers to teachers is high. The degree to which the targeted principals assist teachers in solving problems is high. The degree to which the targeted principals send thank you letters for distinguished teachers and thank teachers in front of their colleagues is high. However, the degree to which the targeted principals provide distinguished teachers with awards is low. The degree to which the targeted principals arrange journeys for teachers is low. The degree to which the targeted principals arrange parties for honouring distinguished teachers is low.
\end{abstract}

Keywords: motivating, basic schools, Ajloun, school principals, teachers. 


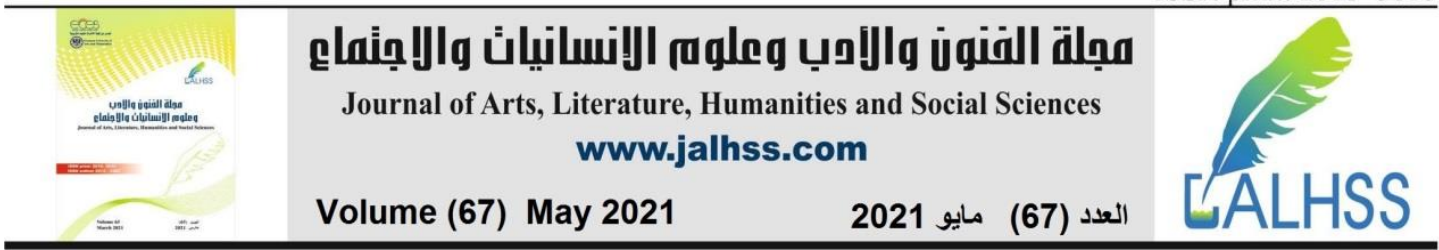

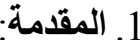

هنالك العديد من التحديات التي نواجه المعلمي، والتي تصعب عليهج أداء مهامهم وتنتر الثعور بالإحباط

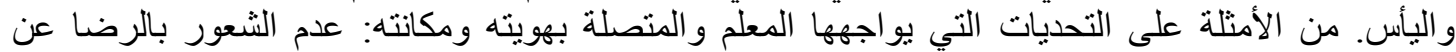

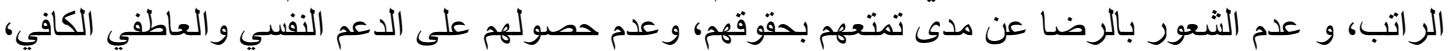

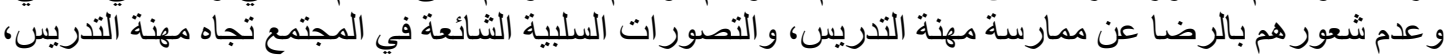

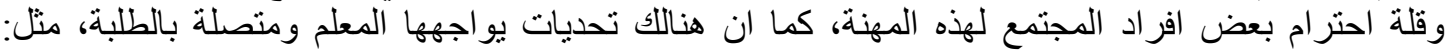

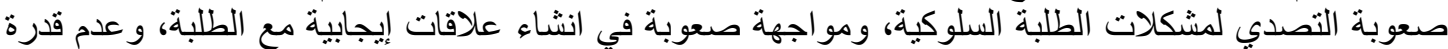

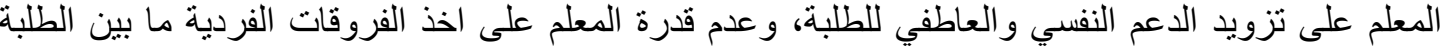

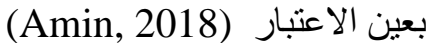

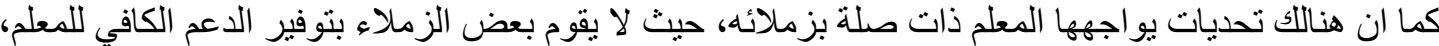

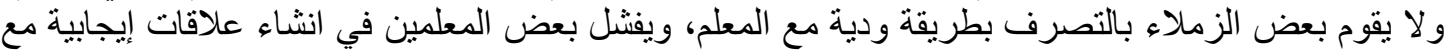

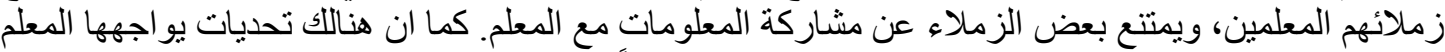

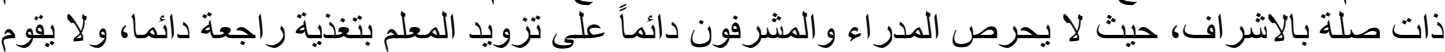

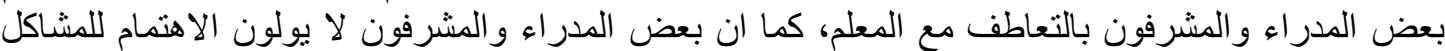

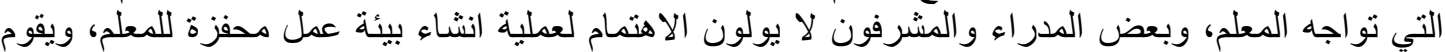

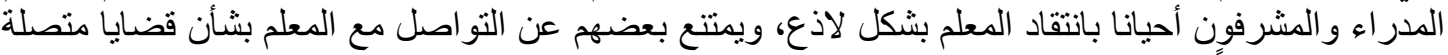

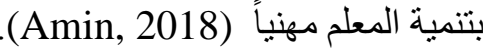

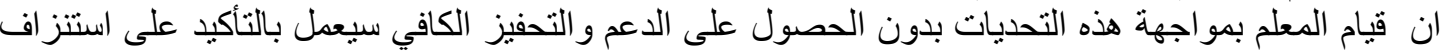

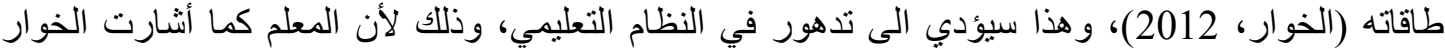

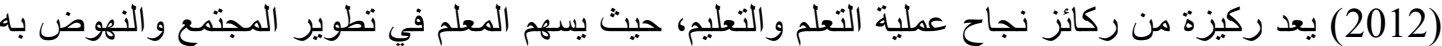

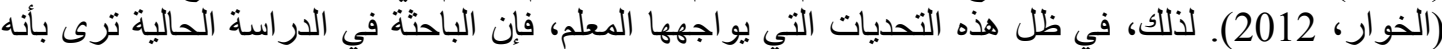

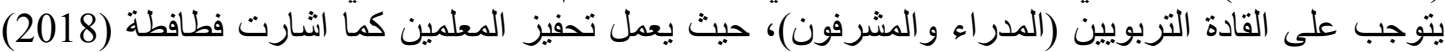

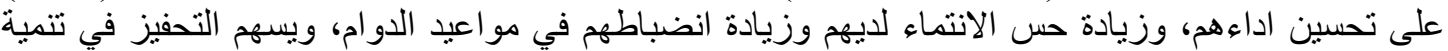

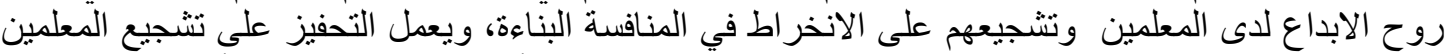

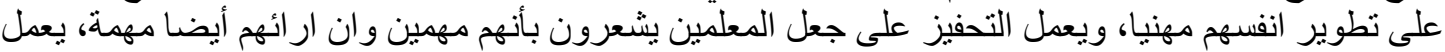

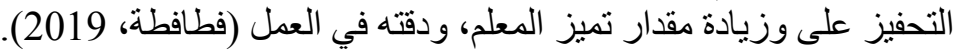

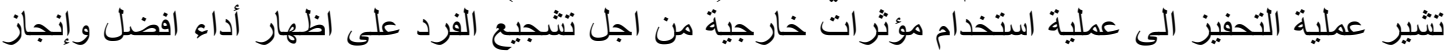

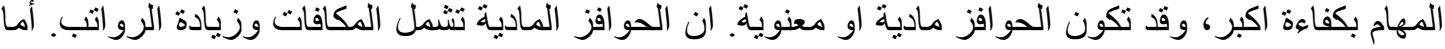

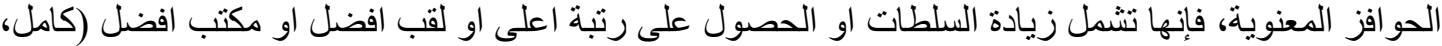

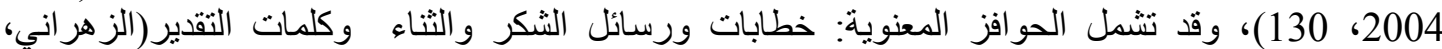

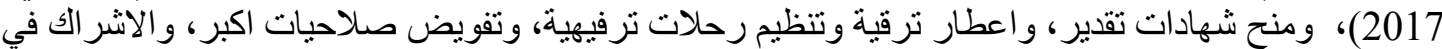

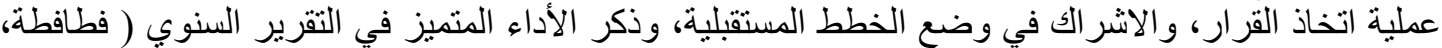

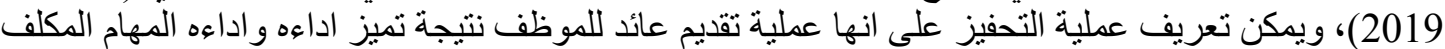
بها بكفاءة (بوحوش و الذنيبات ، 2000) 2000)

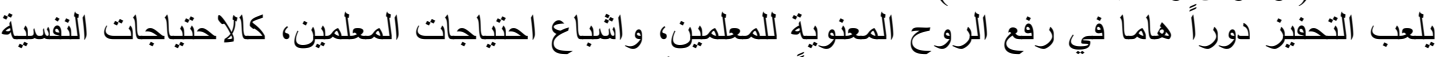

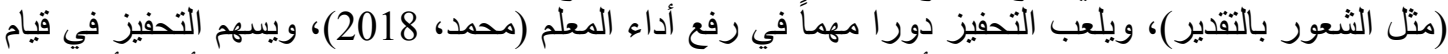

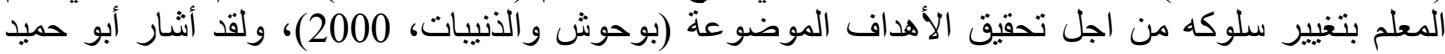

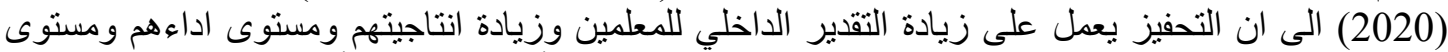

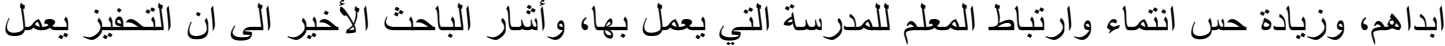

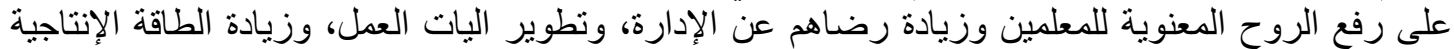

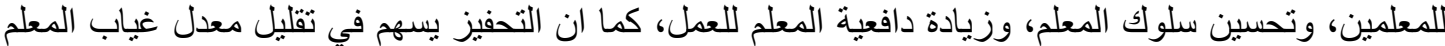




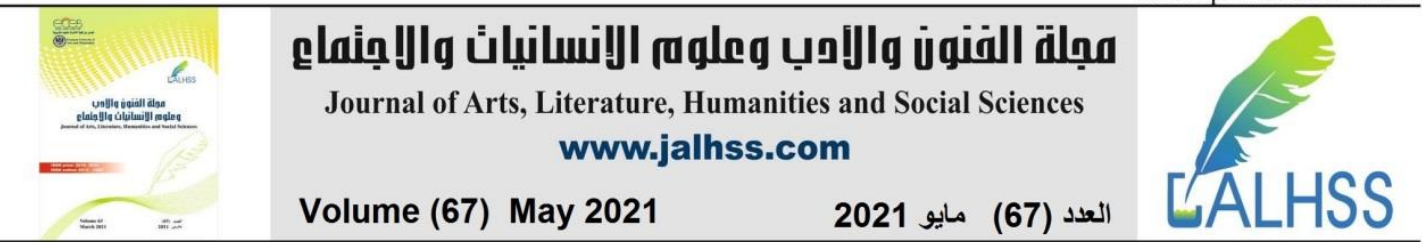

هناللك العديد من طرق واليات التحفيز التي بستطيع القادة التربويين اتباعها من اجل رفع الروح المعنوية

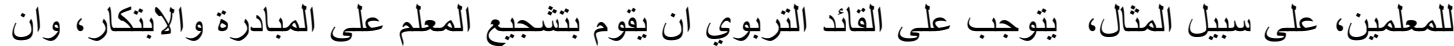

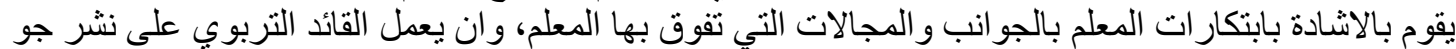

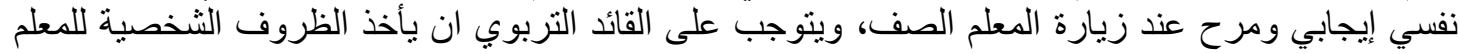

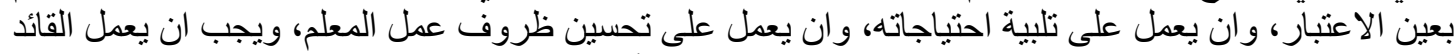
التربوي على الاهتمام بار اء المعلمين في تقييم الطلبة، ويحتر ام أفكار المعلمين في حل المشكلات الصئ الصفية (محمد،

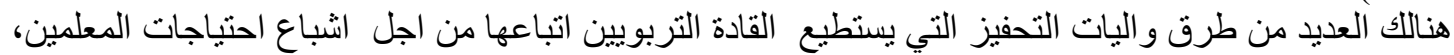

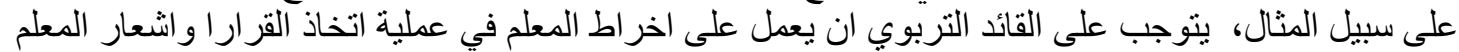

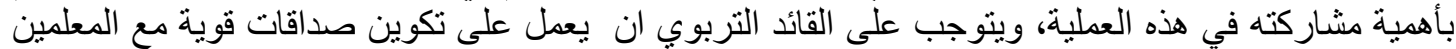

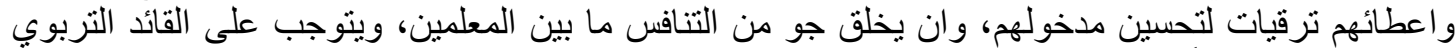

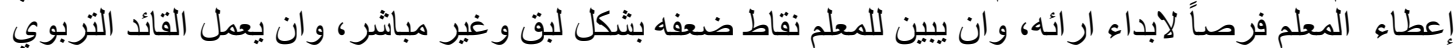

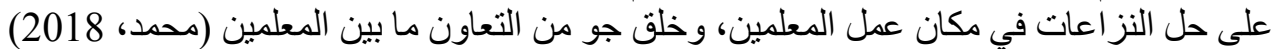

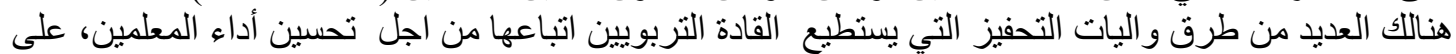

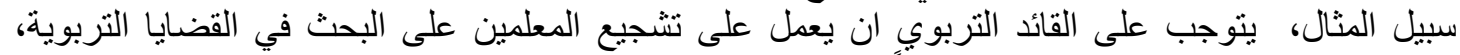

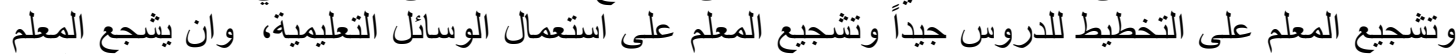

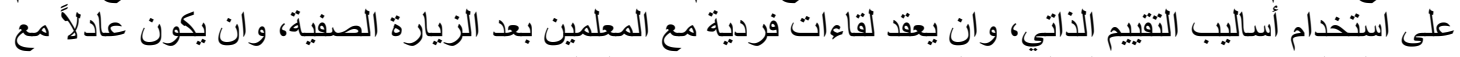

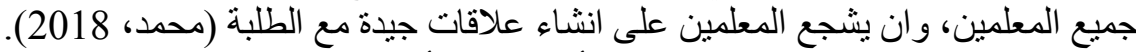

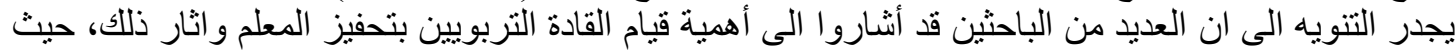

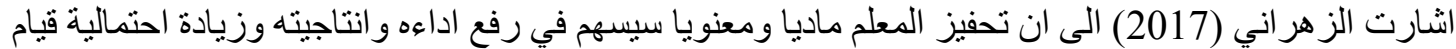

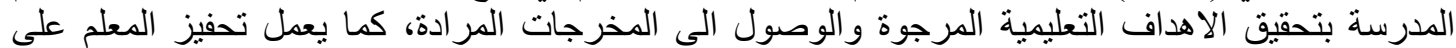

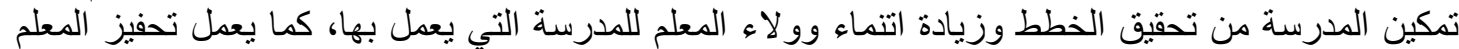

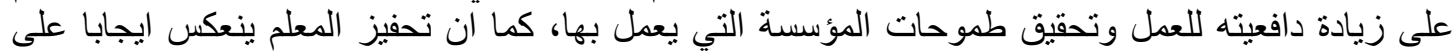

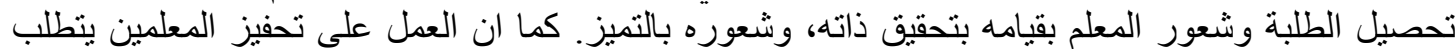

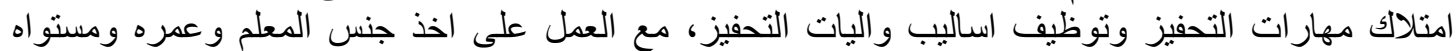

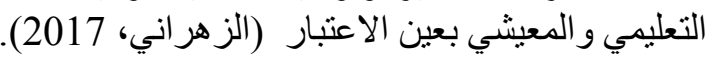

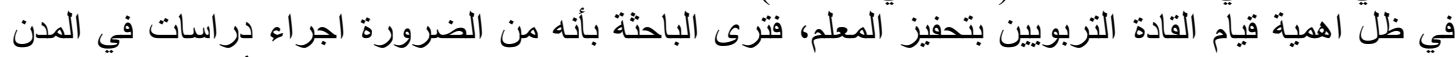

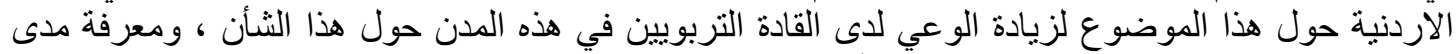

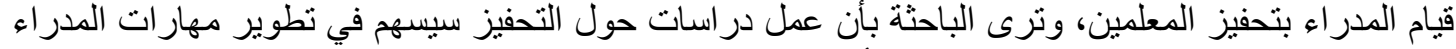

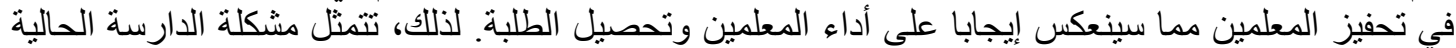
بالسؤال الاتي: (ما درجة ممارسة مديري المدارس الأساسية في محافظة عجلون مهارة تحفيز المعلمين من

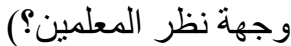

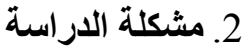

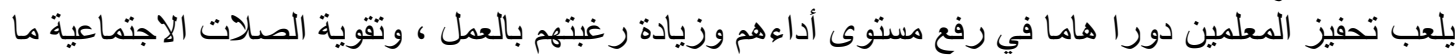

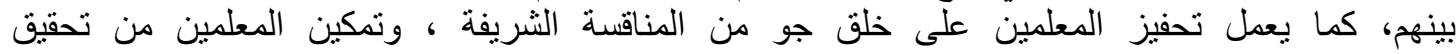

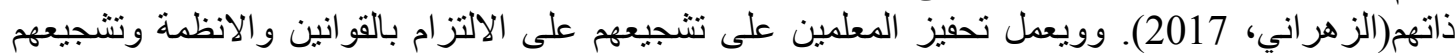

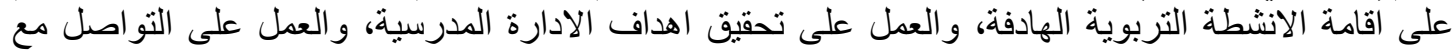

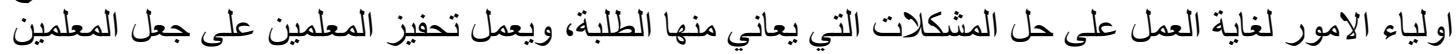

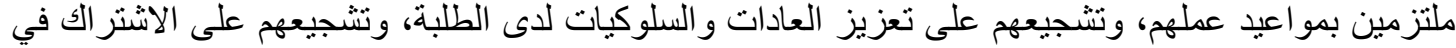

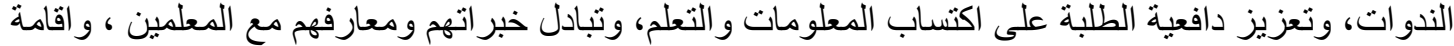

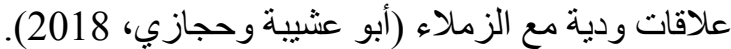

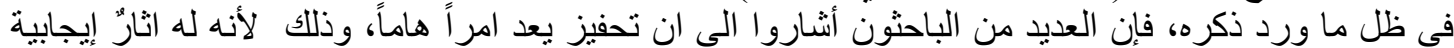

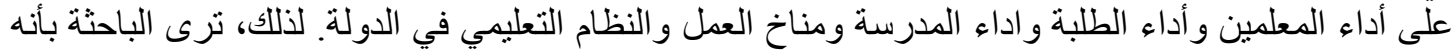




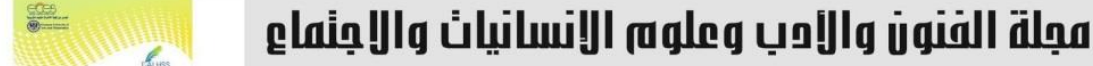 \\ Journal of Arts, Literature, Humanities and Social Sciences www.jalhss.com \\ Volume (67) May 2021 \\ 2021 العدد (67) مايو \\ LALHSS}

يتوجب تسليط الضوء على تحفيز المعلمين. لذلك، تتمثل مشكلة الدارسة الحالية بالسؤال الاتي: (ما درجة ممارسة مديري المدارس الأساسية في محافظة عجلون مهارة تحفيز المعلمين من وجهة نظر المعلمين؟) 3. تهدف الدارسة لمعرفة درجة ممارسة مديري المدارس الأساسية في محافظة عجلون مهارة تحفيز المعلمين من وجهة نظر المعلمين

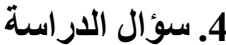
تهدف الدر استة هذه للإجابة على ما يلية ما درجة ممارسة مديري المدارس الأساسية في محافظة عجلون مهارة تحفيز المعلمين من وجهة نظر المعلمين؟

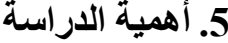
تعد الدر اسة الحمالية هامة، لأنها الدراسة الأولى التي تهدف لمعرفة درجة ممارسة مديري المدارس الأساسية في

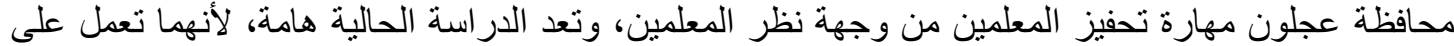
نشر الوعي ما بين صفوف القادة التربويين (المدراء والمشرفين في المدارس) حول أهمية تحفيز المعلمين

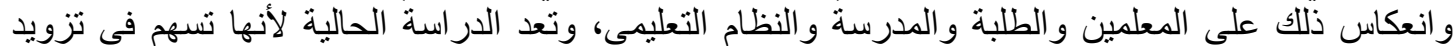

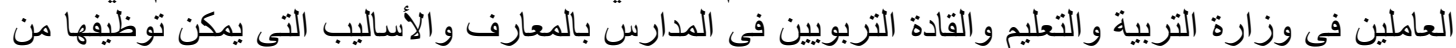
اجل تحفيز المعلمين.

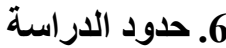

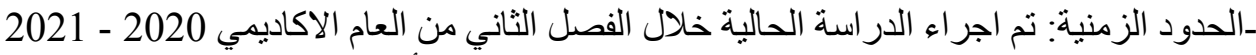

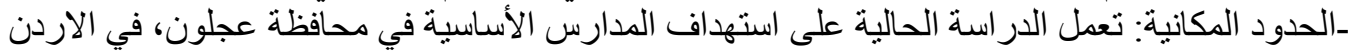

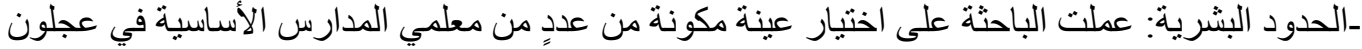

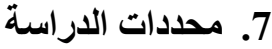
لا يمكن تعميم نتائج الدراسة، وذلك لأن النتائج تختلف باختلاف الأداة ودرجة ثباتها وصدقها وباختلاف خصائص العينة

8. تعريفات الاراسة الإجرائية والنظرية

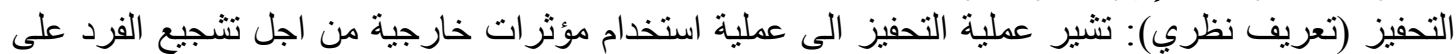

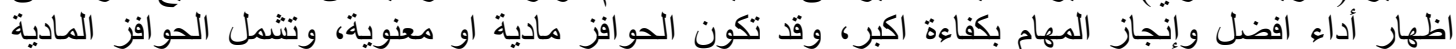

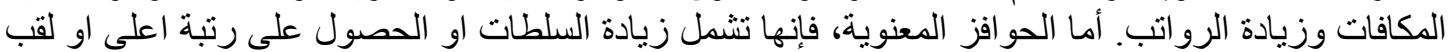
افضل او مكتب افضل (كامل، 2004، 130)، وقد تشمل الحوافز المعنوية: خطابات الثكر والثناء وكلمات ونهات التقدير (الز هر اني، 2017). ـالمدارس الأساسية (تعريف نظري): المدارس التي تحتوي على الصفوف من الصف الأول حتى الصف العاثر ـالتحفيز (تعريف اجرائي): يشير هذا المصطلح الى توظيف مؤثرات خارجية من قبل مدر اء مديري المدارس الأساسية في محافظة عجلون من اجل تشجيع المعلمين في هذه المدارس على تحسين التهين ادائهم و العمل بكفاءة. محافظة عجلون (تعريف نظري): هي احدى المحافظات الو اقعة في اقليم الشمال في الاردن الثن

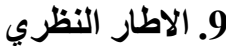
9.1

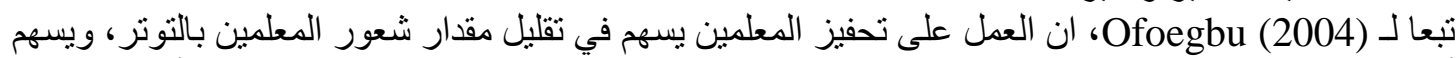
أيضا في تحسين فعالية المعلمين في إدارة الغرفة الصفية، ويسهم تحفيز المعلمين في تحسين أداء الدين المدرسة

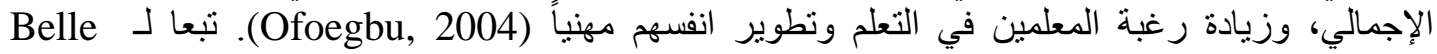

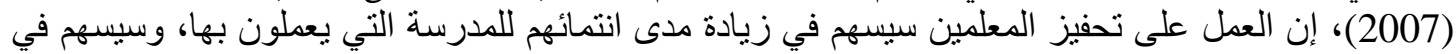

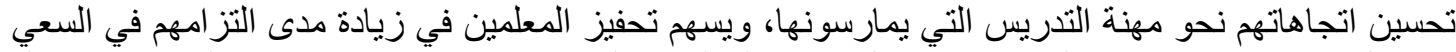

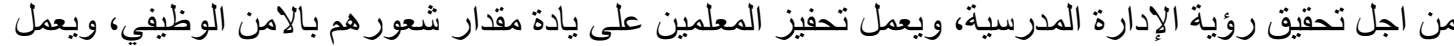

تحفيز المعلمين على زيادة دافعيتهم للعمل (Belle, 2007)

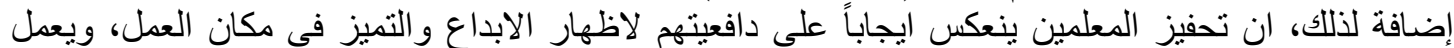
تحفيز المعلمين على رفع الروح المعنوية للمعلمين وبث الامل في نفوسهم، ويعمل تحفيز المعلمين على زيادة مستوى رضاهم الوظيفي، وزيادة احتمالية تحقيق اهداف الإدارة المدرسية ورسالتها، ويسهم تحفيز المعلمين في 


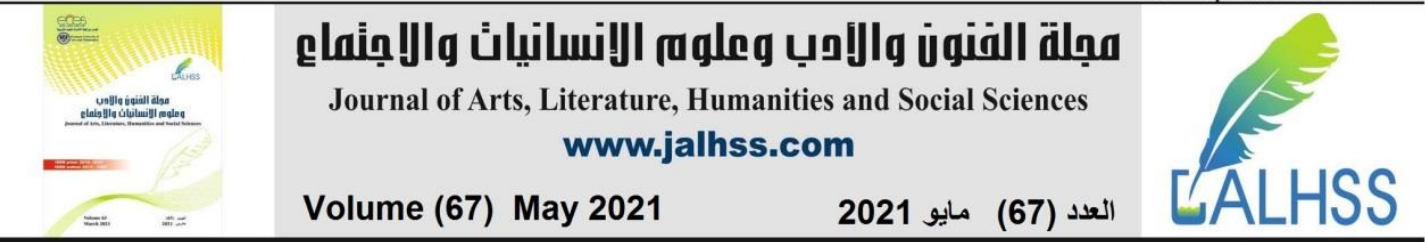

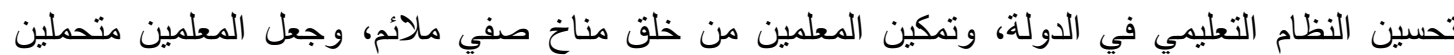

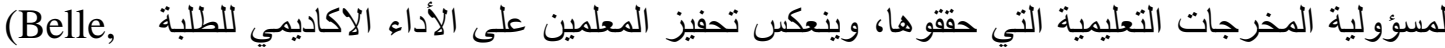
(2007. أشار العبداله، و رحمن (2012) التى ان تحفيزي العاملين ينعكس إيجابا على تفكيرهم الابتكاري

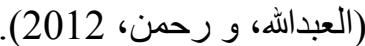

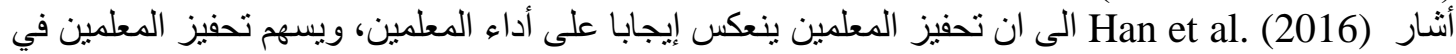

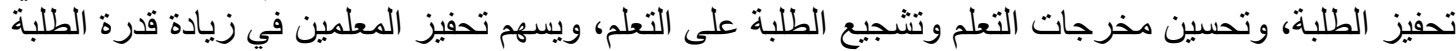

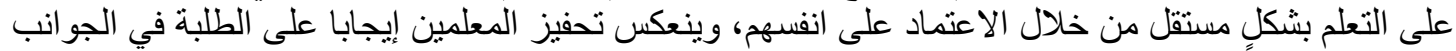

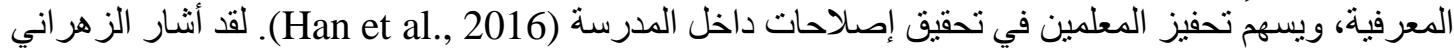

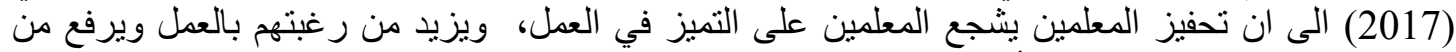

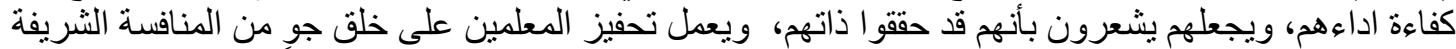

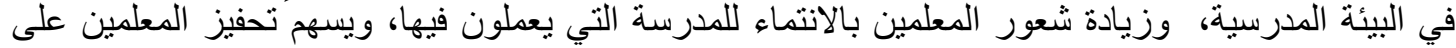

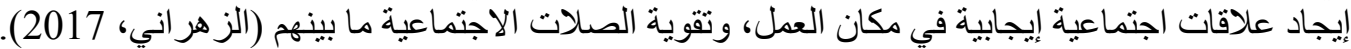

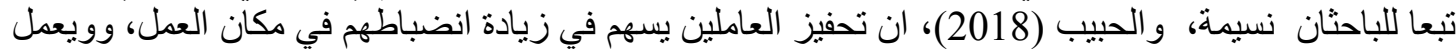

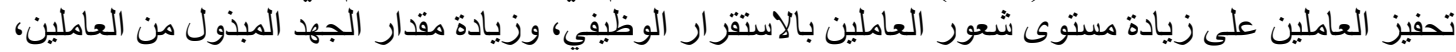

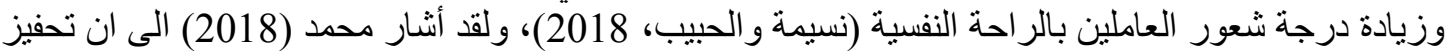

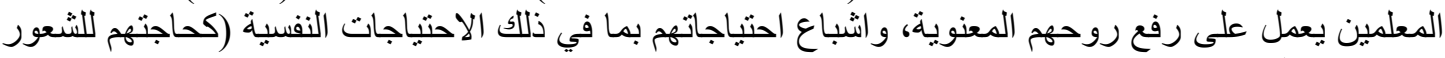

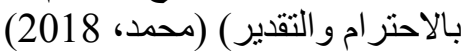

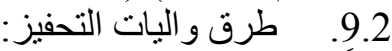

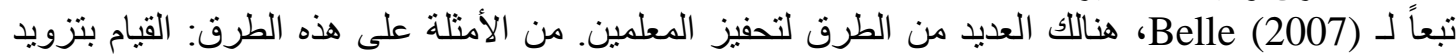

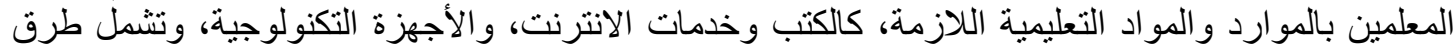

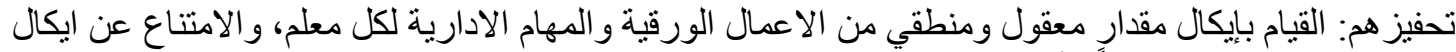

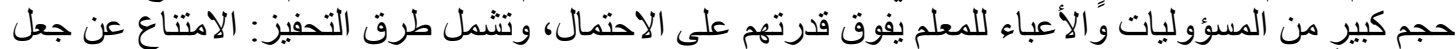

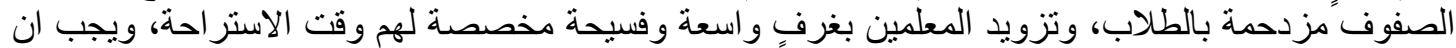

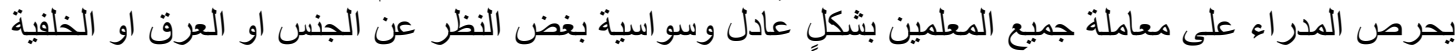

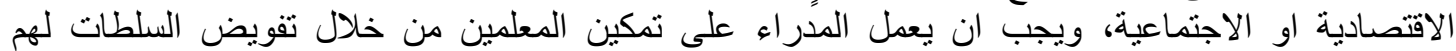

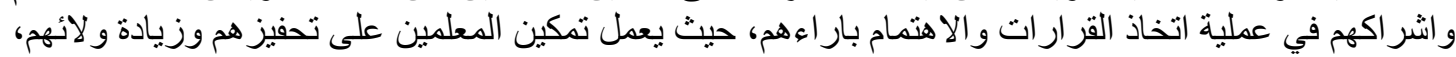
وزيادة حرصهم على تحقيق اهداف الإدارة المدرسية (Belle, 2007)

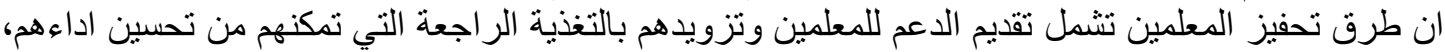

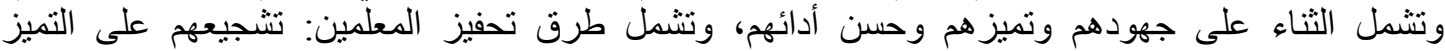

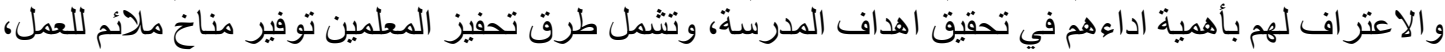

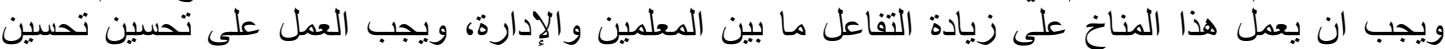

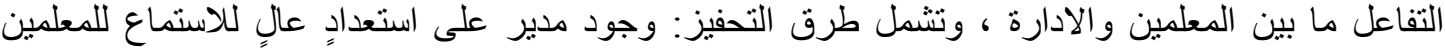

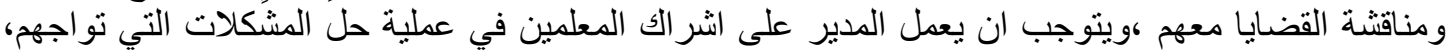

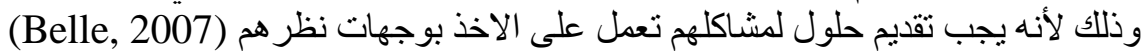

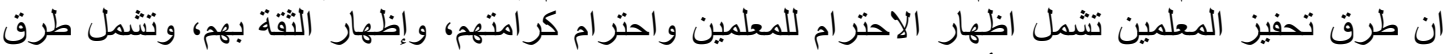

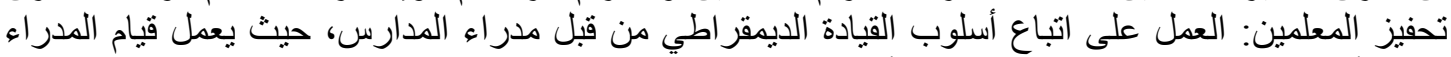

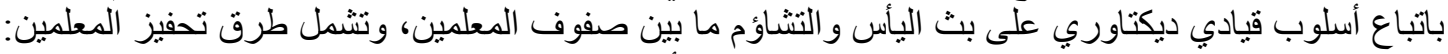

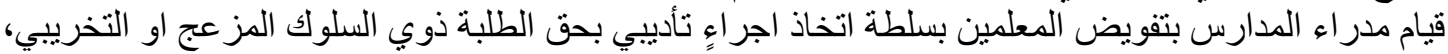

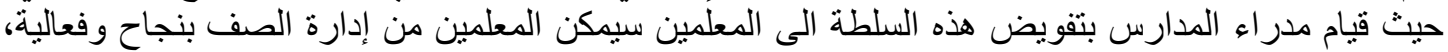

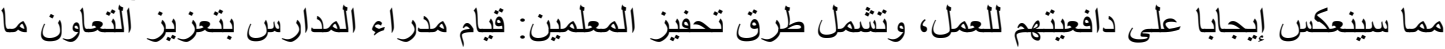

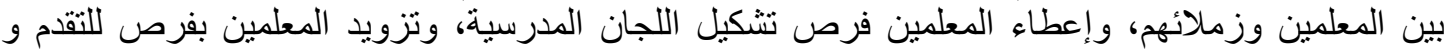

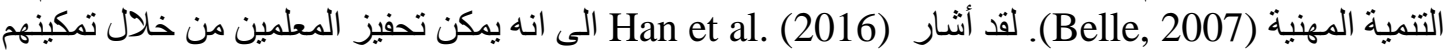

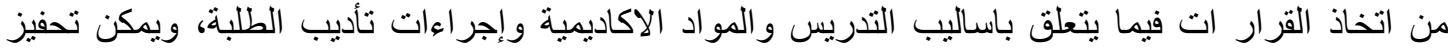

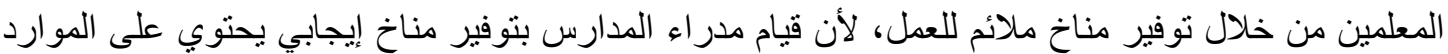




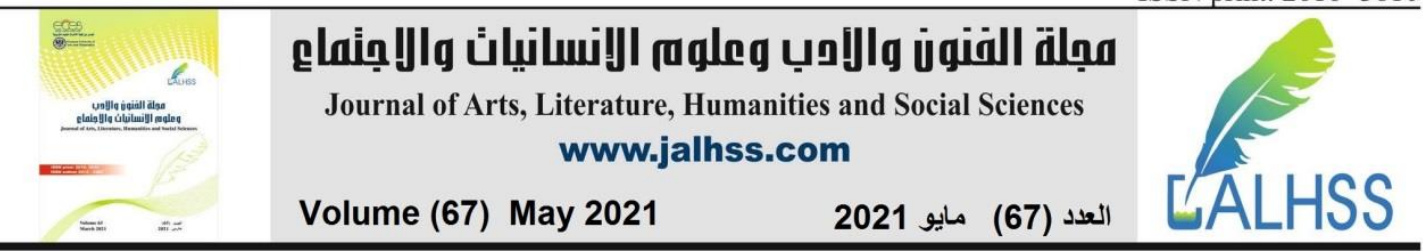

التي يحتاجها المعلمين للعمل سيسهل على المعلمين أداء معامهم، وسيجعل المعلمين مقبلين على أداء مهامهم

وبذل الجهود (Han et al., 2016)

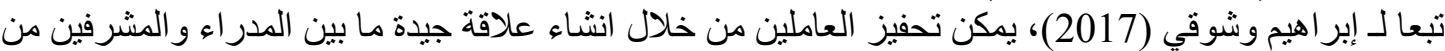

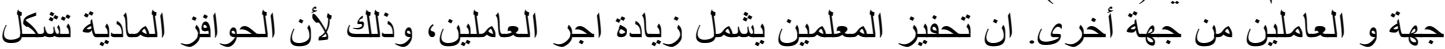

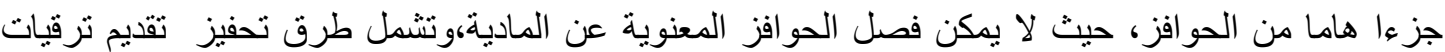

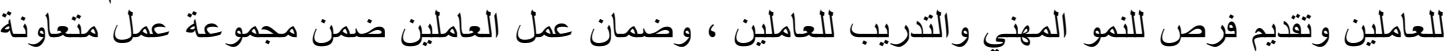

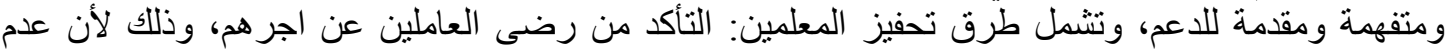

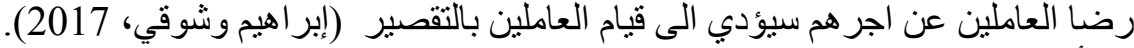

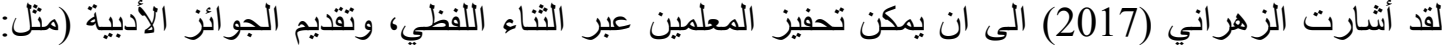

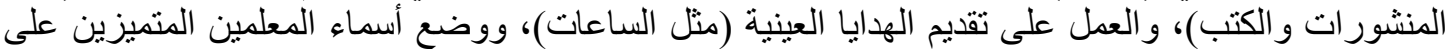

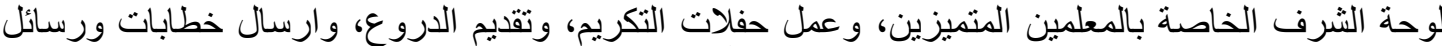

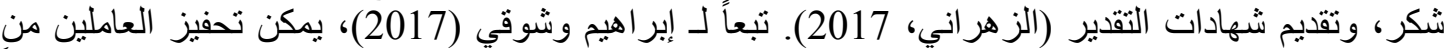

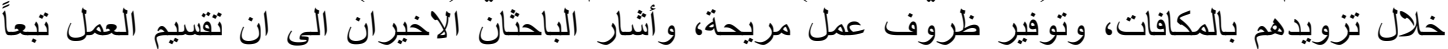

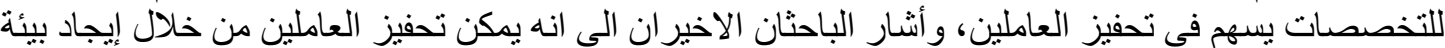

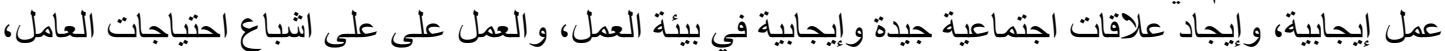

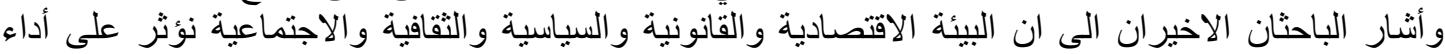

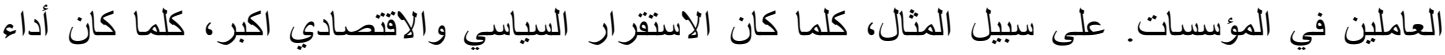

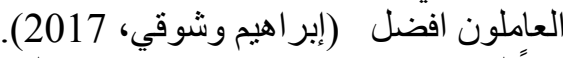

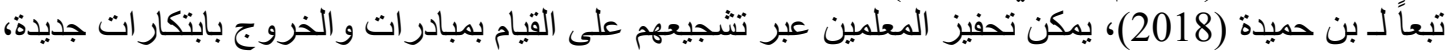

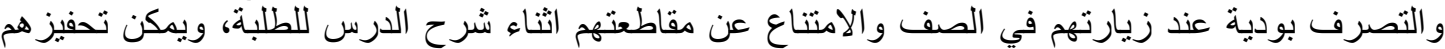

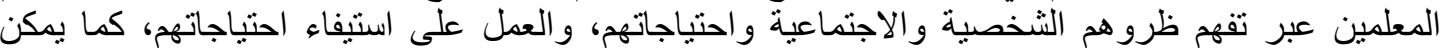

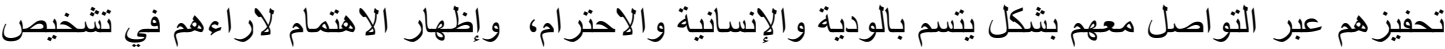

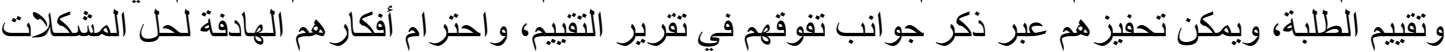

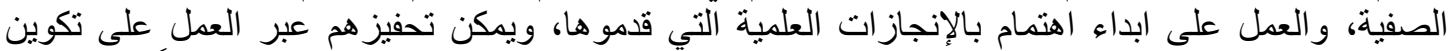

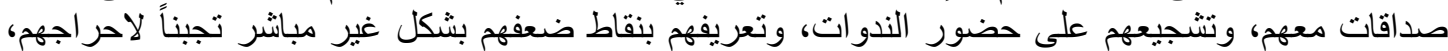

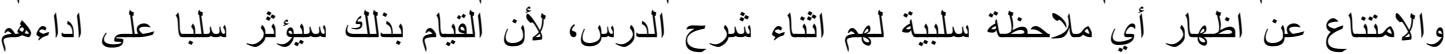

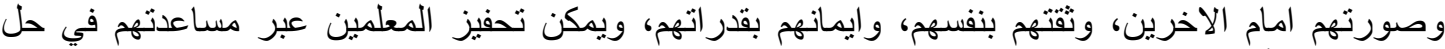

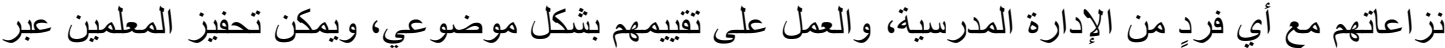

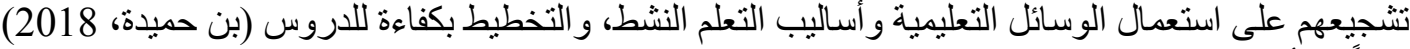

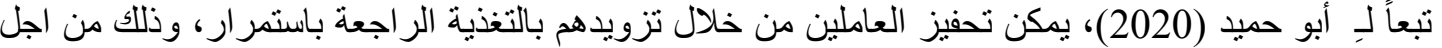

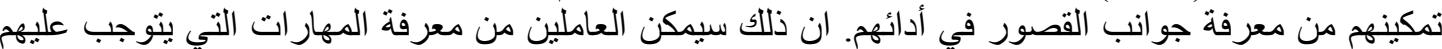

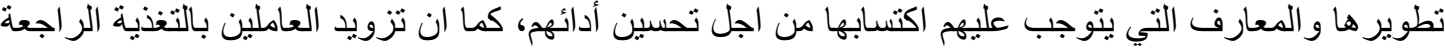

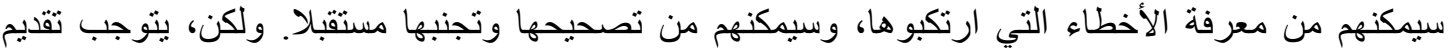

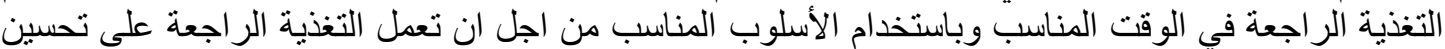

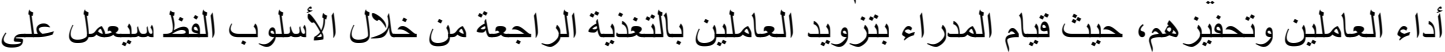

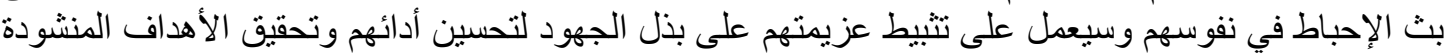

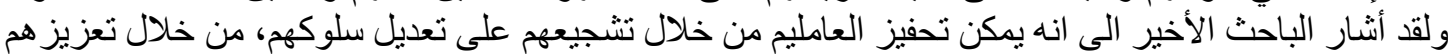

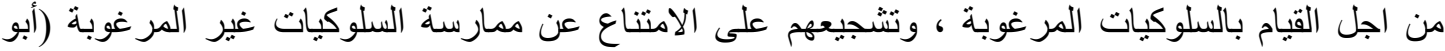

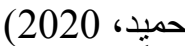
تبعاً لِ أبو حميد (2020)، بمكن تحفيز العاملين من خلال اشراكهم في عملية وضع الأهداف والخطط،

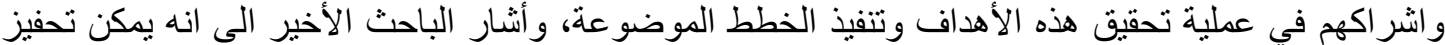

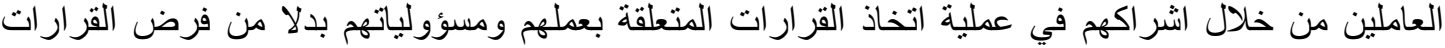

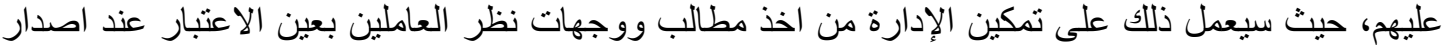
القرارات النهائية، ولقد أشار الباحث الأخبر الى انه يمكن تحفيز العاملين من خلال اشتعار هم بأههميتهم في مكان الأن 


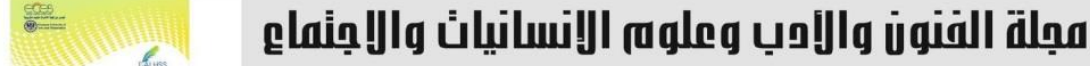 \\ Journal of Arts, Literature, Humanities and Social Sciences www.jalhss.com

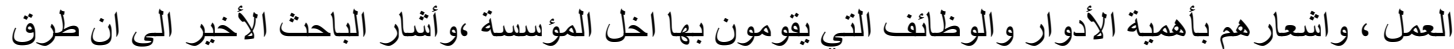

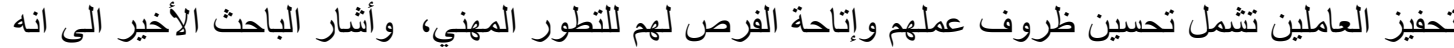

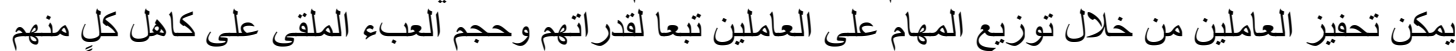
(أبو حميد، 2020).

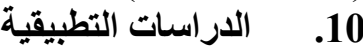

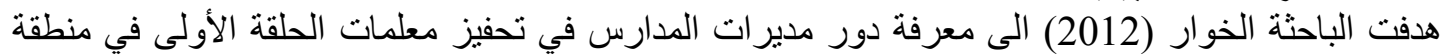

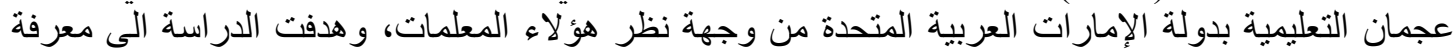

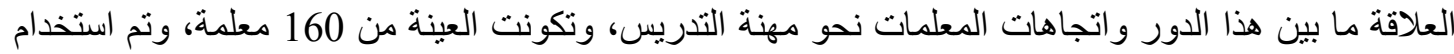

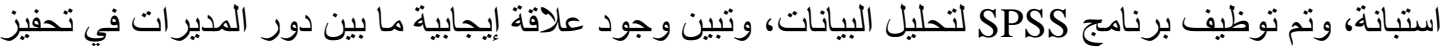

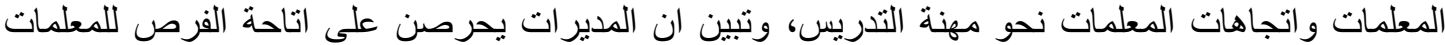

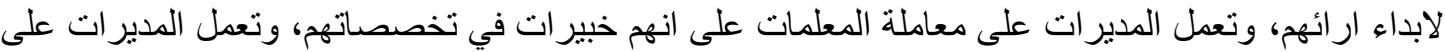

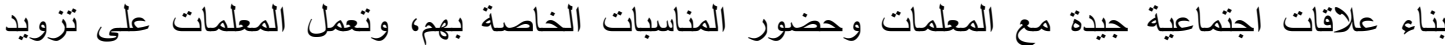

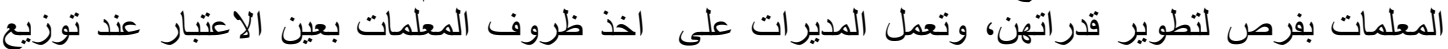

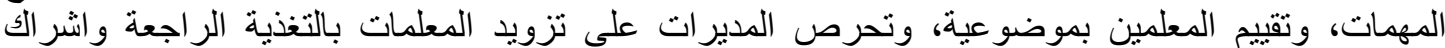

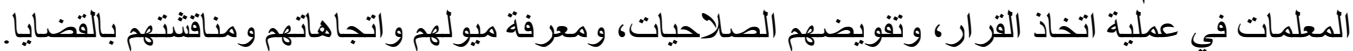

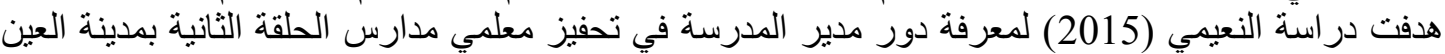

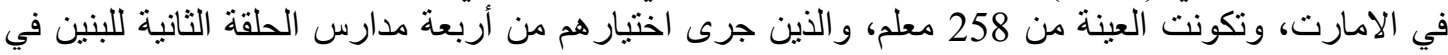

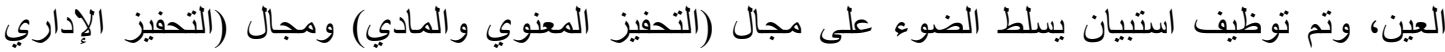

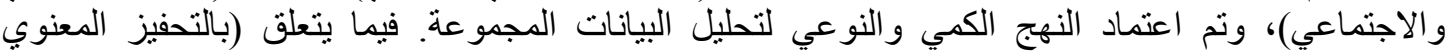

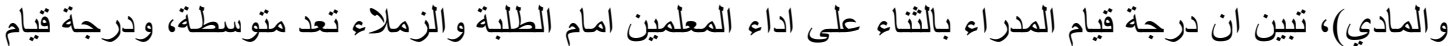

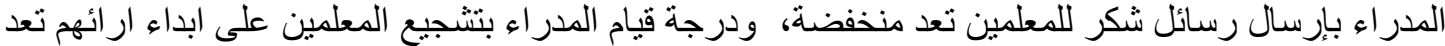

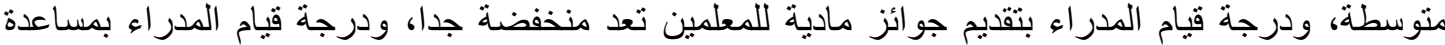
المعلمين في حل المشكلات تعد منخفضة، ودرجة قيام المئة المدراء بتشجيع المعلمين على استخدام طرق حديثة للتنريس تعد متوسطة (النعيمي، 2015). فيما يتعلق بمجال (التحفيز الإداري والاجتماعي)، تبين ان درجة درئ مراعاة المدراء للظروف الاجتماعية تعد

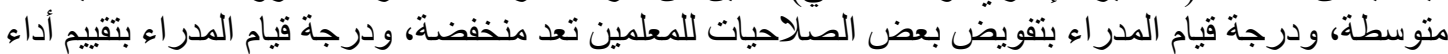

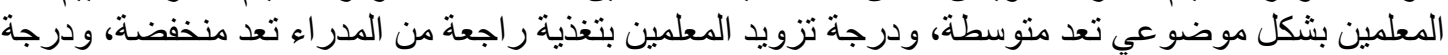

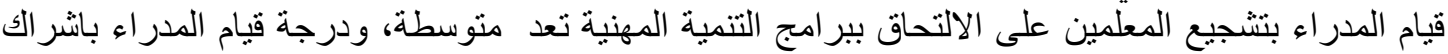

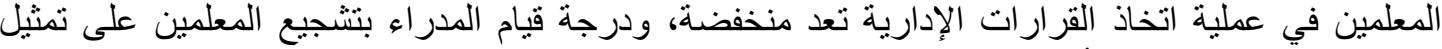

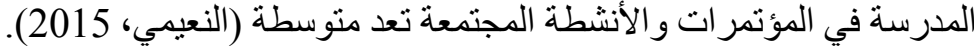

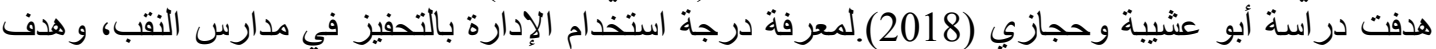

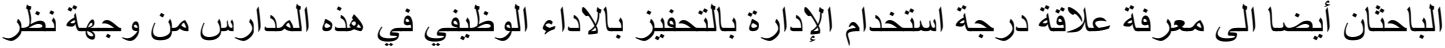

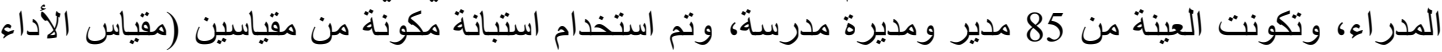

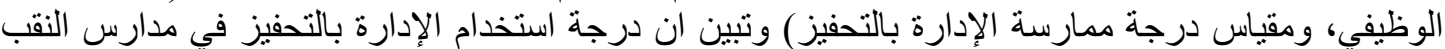

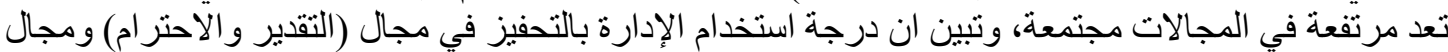

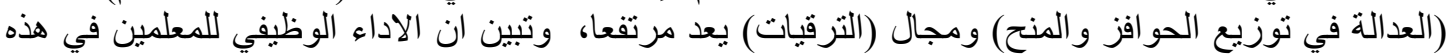

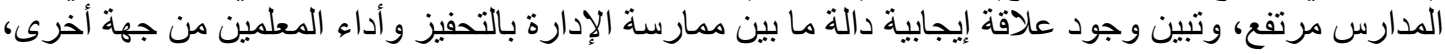

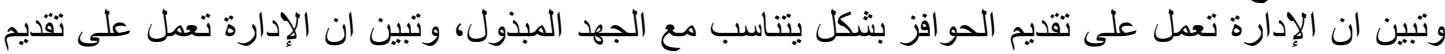

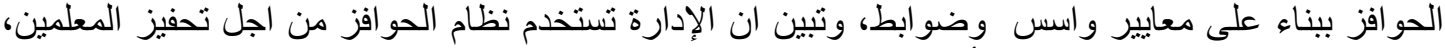

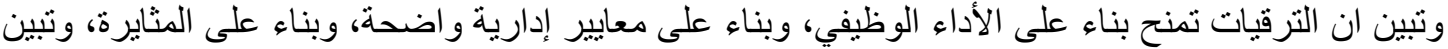

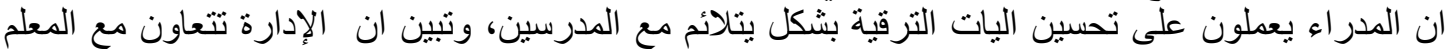

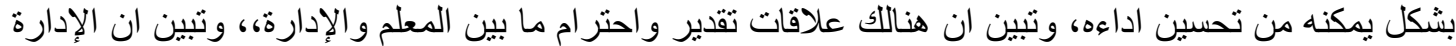

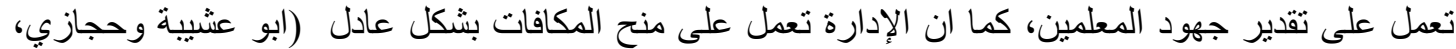




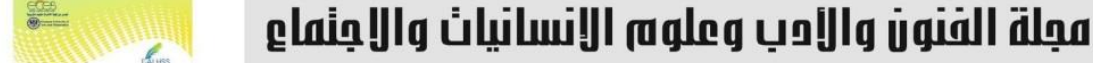 \\ Journal of Arts, Literature, Humanities and Social Sciences www.jalhss.com \\ Volume (67) May 2021 \\ 2021 العدد (67) مايو

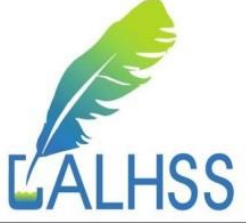

هدفت در اسة فطافطة (2018) الى معرفة مدى قيام مدر اء المدارس في محافظة الخليل بتوظيف أساليب تحفيز

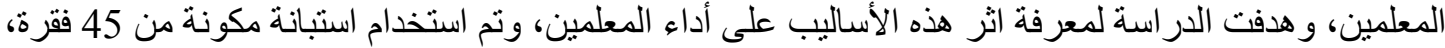
وتكونت العينة من 158 مدير ومديرة مدرسة، و 460 معلم ومعلمة، والذين جرى اختى اختيار هم عبر الأسلوب

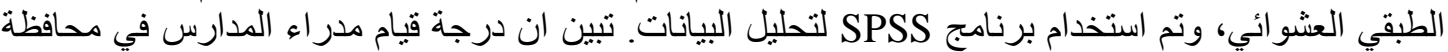

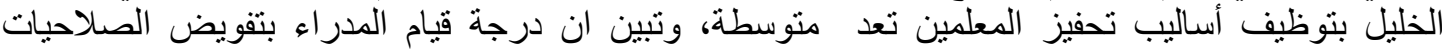

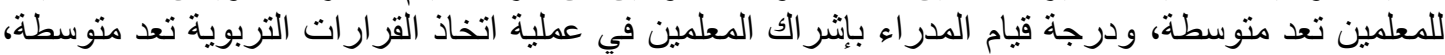

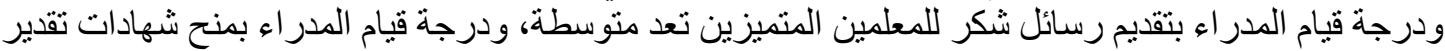

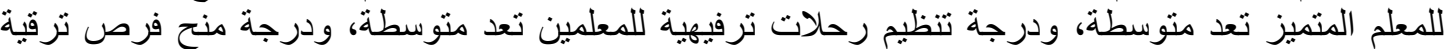
للمعلمين من قبل المدر اء تعد متوسطة، وتبين ان درجة اشراك المعلمين من قبل المدر اء في وضعة فئع الخطط المستقبلية تعد متوسطة من فينة هدفت در اسة المحرج (2020) الى تسليط الضوء عدؤ على واقع تحفيز مديري المدارس في مدينة الرياض للعاملين

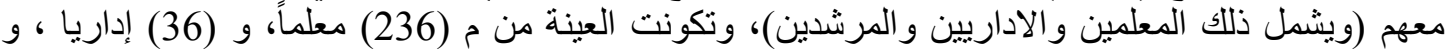

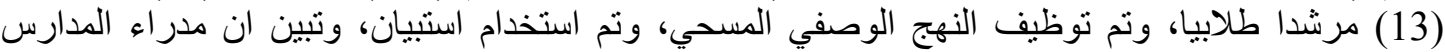

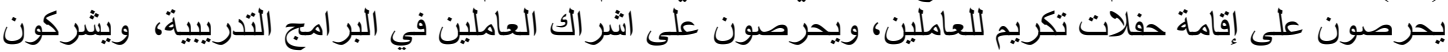

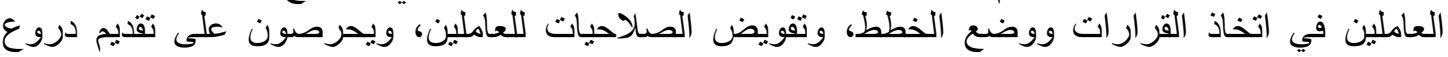

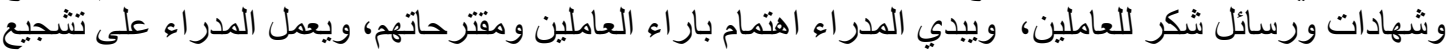

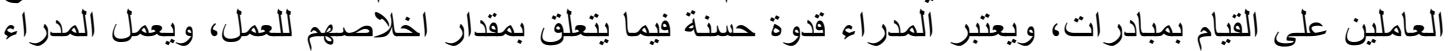

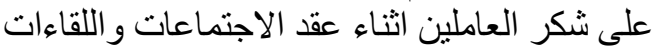
11 11.1 تم توظيف النهج الوصفي التحليلي، حيث يعد هذا النهج الأنسب لدر اسة ووصف اتجاهات المبحوثين

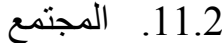
يتمثل مجتمع الدر اسة بكافة المعلمين و المعلمات العاملين في المدارس الأساسية في محافظة عجلون، في الاردن 11.3. 11.3 عملت الباحثة على توزيع الاستبيان الكترونيا على 115 معلم ومعلمة من ثماني مدارس حكومية اساسية في

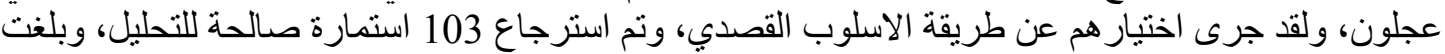

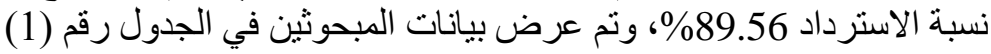

\begin{tabular}{|c|c|c|c|}
\hline النسبة & التكر ار & الفئة & المتغير \\
\hline 38.834 & 40 & ذكور & \multirow[t]{2}{*}{ لجنس } \\
\hline 61.165 & 63 & اناث & \\
\hline 90.2912 & 93 & بكالوريوس & \multirow[t]{4}{*}{ المؤ هل الاكاديمي } \\
\hline 5.825 & 6 & ماجستير & \\
\hline 3.8834 & 4 & دبلوم عالي & \\
\hline 0 & 0 & دكتور اه & \\
\hline
\end{tabular}

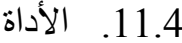

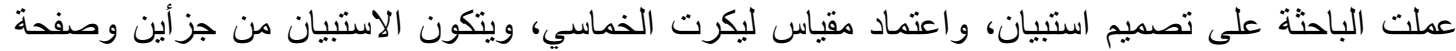

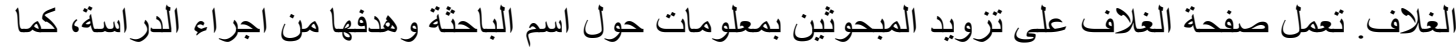

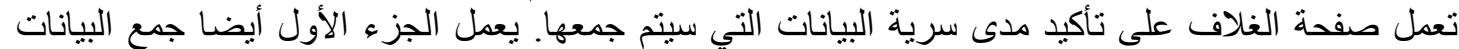

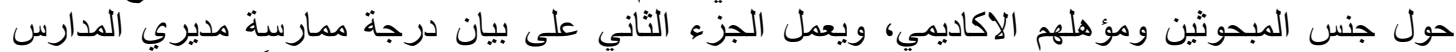

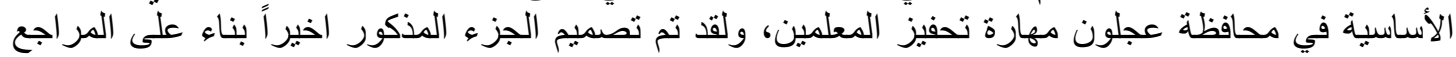

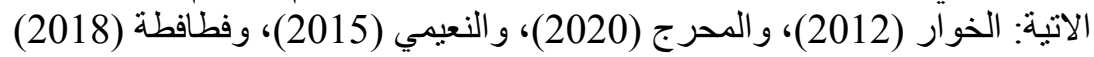




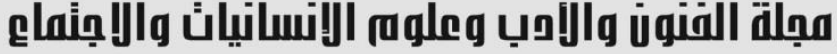 \\ Journal of Arts, Literature, Humanities and Social Sciences www.jalhss.com}

\section{Volume (67) May 2021}

العدد (67) م مايو 2021

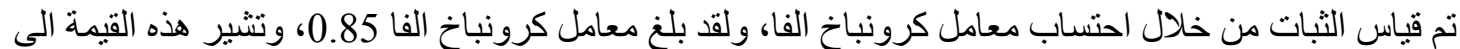

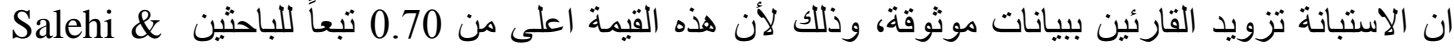

.Farhang (2019) صدق الأداة

لقد تم عرض النسخة الأولية من الاستبيان على اثنان من الخبر اء المختصين في مجال القيادة والإدارة التربوية،

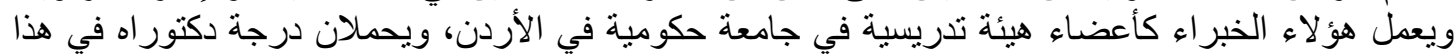

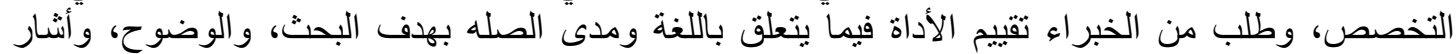

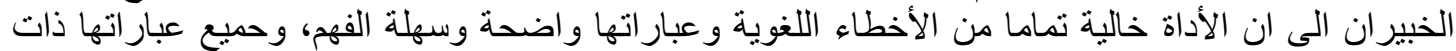

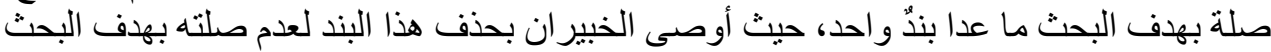
11.6 1. 11. ادوات تحليل البيانات: تم توظيف برنامج (SPS) لتحليل البيانات ومعالجنها، وتم استخدام أساليب التحليل الوصفي، وتتمل هذه الأساليب بالمنتوسطات و التكر ار ات و النسب و الانحر افات التات المعيارية

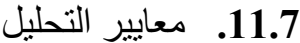
من اجل تصنيف المتوسطات، نم اعتماد المعايير المذكورة ادناه، وتعد هذه المعايير معايير إحصائية الجدول (2): المعايير التي تم توظيفها لتصنيف التصنيف المتوسطات التونير

\begin{tabular}{|c|c|c|}
\hline الاتجاه & المستوى & المدى \\
\hline سلبي & منخفض & 2.33 او اقل \\
\hline حيادي & متوسط & $3.66-2.34$ \\
\hline إيجابي & مرتفع & 3.67 او اكثر \\
\hline
\end{tabular}

Aljbour (2020): (المصدر (ك)

تم اعتماد مقياس ليكرت الخماسي المكون من الفئات و النقاط المدرجة ادناه الجدول (3): فئات ونقاط مقياس ليكرت الخماسي المكون من خمس فئات

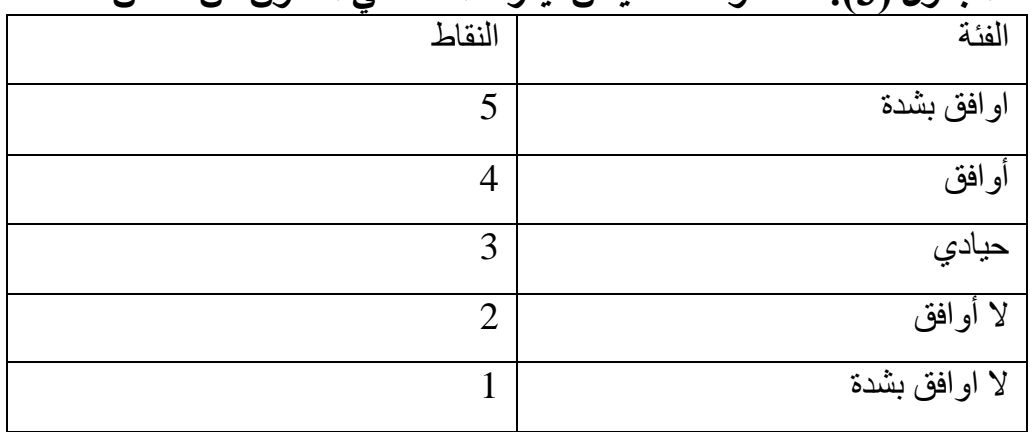

Aljbour (2020) : المصدر

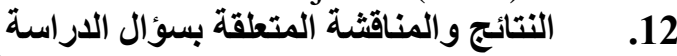

سؤال الدر اسة: ما درجة ممارسة مديري المدارس الأساسية في محافظة عجلون مهارة تحفيز المعلمين من وجهة

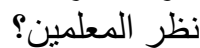

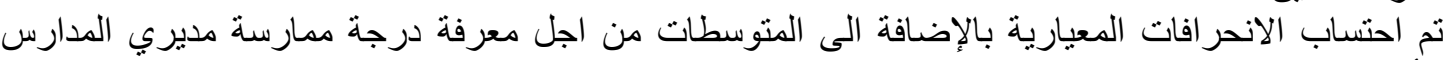

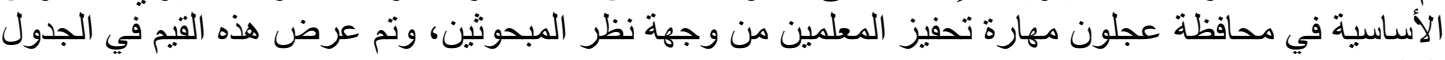
الجدولي (4): درجة ممارسة مديري المدارس الأساسية في محافظة عجلون مهارة تحفيز المعلمين من وجهة نظر المبحوثين مين

\begin{tabular}{|c|c|c|c|c|c|}
\hline الاتجاه & 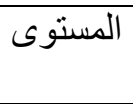 & الالانحراف & الحستوسي & 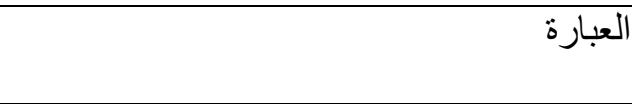 & 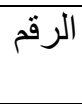 \\
\hline & & & & ان مديري/مديرتي في المدرسة يعمل/تعمل على & \\
\hline إيجابي & مرتفع & 0.27 & 4.84 & اتاحة الفرص لي لابداء ر ايبي ا & .1 \\
\hline
\end{tabular}




\begin{tabular}{|c|c|c|c|c|c|c|}
\hline \multirow{2}{*}{\multicolumn{2}{|c|}{ 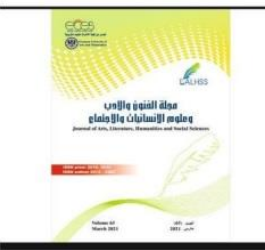 }} & \multicolumn{3}{|c|}{ 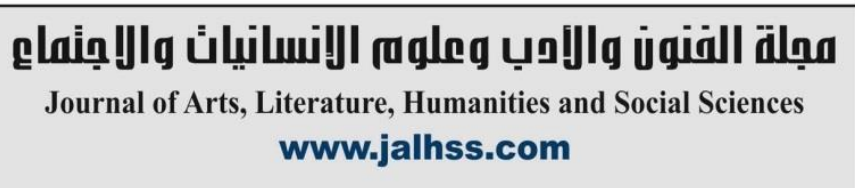 } & \multirow{2}{*}{\multicolumn{2}{|c|}{ HALHSS }} \\
\hline & & Volume (6 & ) May & العدد (67) مايو 2021 & & \\
\hline إيجابي & مرتفع & 0.34 & 4.95 & غذية الر اجعة دائماً & تزويدي بالت & .2 \\
\hline إيجابي & مرتفع & 0.25 & 4.67 & عملية اتخاذ القرار & اشر اكي في & .3 \\
\hline إيجابي & مرتفع & 0.69 & 4.79 & أ من الصلاحيات لي & تفويص عدد & .4 \\
\hline سلبي & منخفض & 0.17 & 2.24 & مادية للمعلمين المتميزين & تقديم جو ائز & .5 \\
\hline إيجابي & مرتفع & 0.29 & 4.80 & لمين في حل المشكلات & مساعدة اله & .6 \\
\hline إيجابي & مرتفع & 0.38 & 4.71 & ل شكر للمعلمين المتميزين & ارسال رسا: & .7 \\
\hline حيادي & متوسط & 0.45 & 3.61 & كوضو عي & تقييمي بشكل & .8 \\
\hline سلبي & منخفض & 0.53 & 2.19 & ت ترفيهية للمعلمين & تتظيم رحلا & .9 \\
\hline سلبي & منخفض & 0.82 & 2.13 & ك تكريم للمعلمين & اقامة حفلات & .10 \\
\hline إيجابي & مرتفع & 0.44 & 4.69 & ي القبام بمبادر ات & تشجيعي عل & .11 \\
\hline إيجابي & مرتفع & 0.76 & 4.53 & ن المتميزين امام زملائهر و الثناء عليهح & شكر المعلمبر & .12 \\
\hline إيجابي & مرتفع & 0.35 & 4.46 & ي الالتحاق ببر امج التندريب المهني & تشجيعي عل & .13 \\
\hline إيجابي & 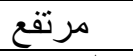 & 0.44 & 4.04 & & القيمة الاجد & \\
\hline
\end{tabular}

*المصدر: تم اعداد الاستبانة من قبل الباحثة بناء على المراجع الاتية: الخوار (2012)، و المحرج (2020)، و النعيمي (2015)، وفطافطة (2018)

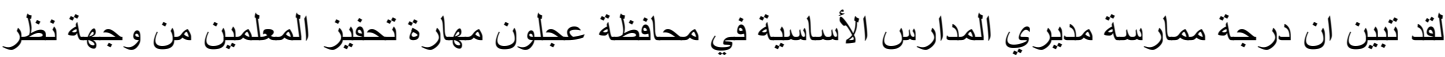

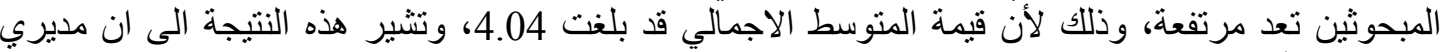

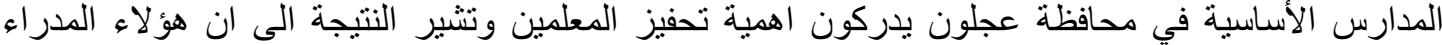

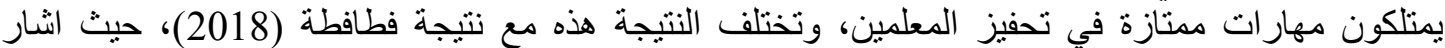

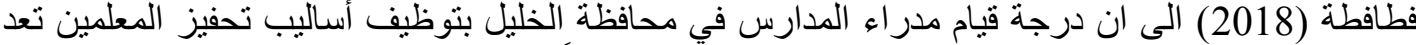

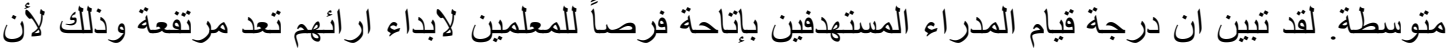

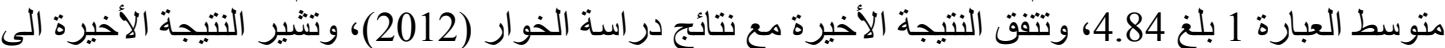

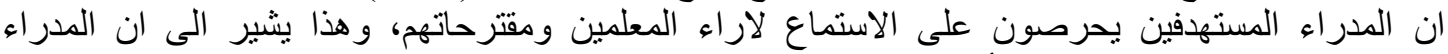
المستهدفين يحرصون على اتباع الأسلوب الديمقر اطي في الأني الإدادارة.

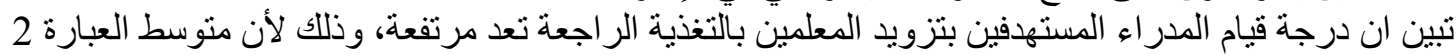

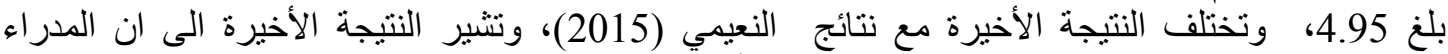

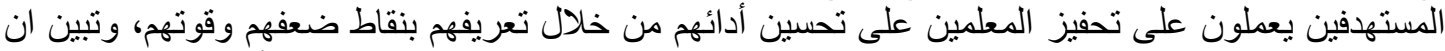

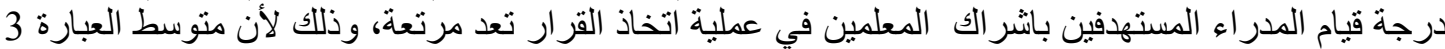

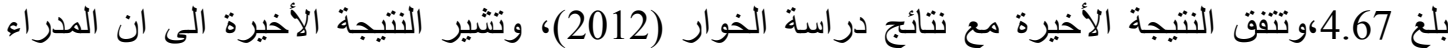

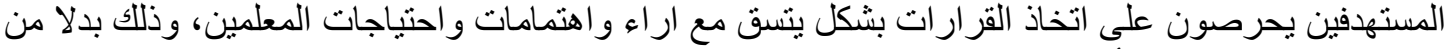

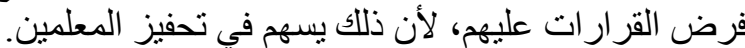

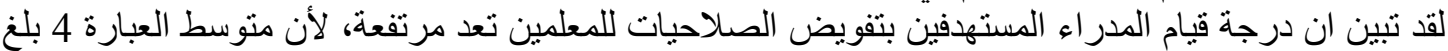

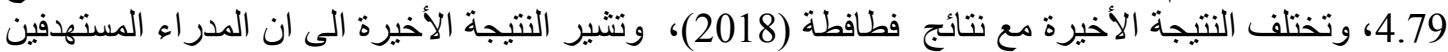

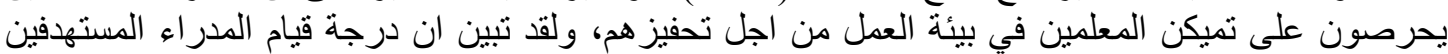

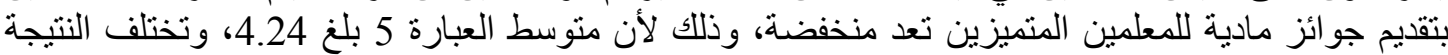

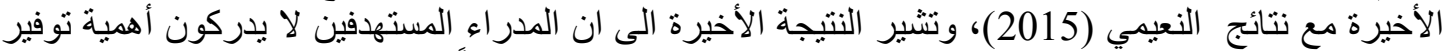

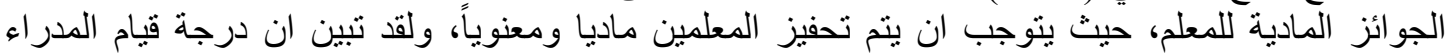

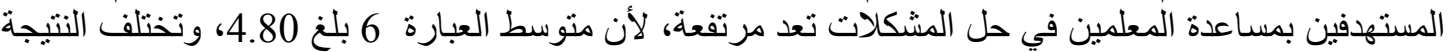

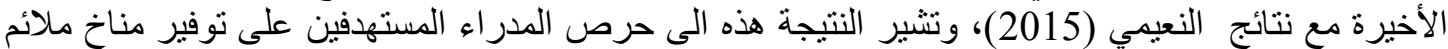

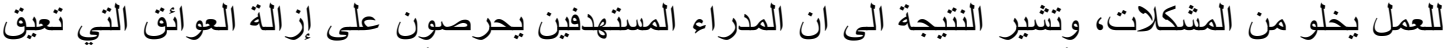

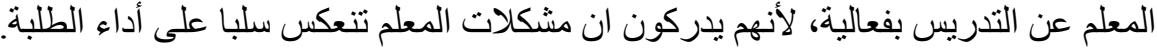

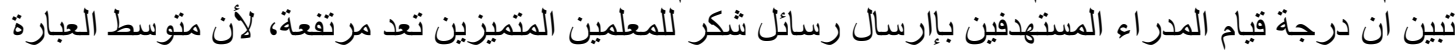
7 بلغ 4.71، و وتختلف النتيجة هذه مع نتيجة فطافطة (2018)، وتثير النتيجة النئة الأخيرة الى الى ان المدراء 


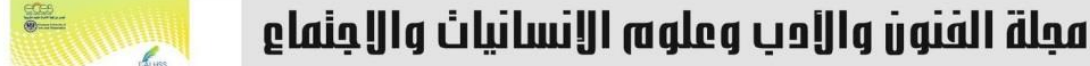 \\ Journal of Arts, Literature, Humanities and Social Sciences www.jalhss.com \\ Volume (67) May 2021 \\ العدد (67) مايو 2021 \\ ¿ÁLHSS}

يحرصون على الثناء على المعلمين و الاعتر اف بتميز هم، وأهمية جهودهم، ويعمل ذلك على رفع الروح المعنوية

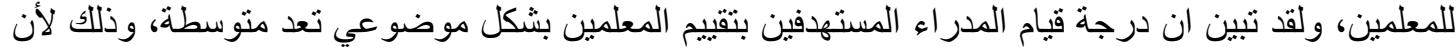

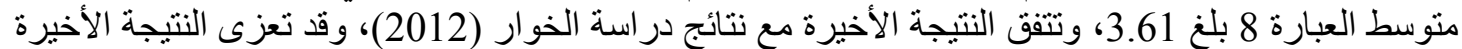

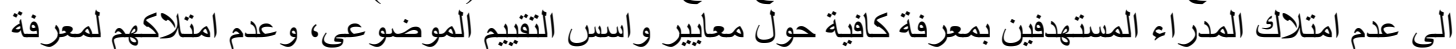
كافية حول أساليب التقييم الحديثنة

لقد تبين ان درجة قيام المدر اء المستهدفين بتتظيم رحلات ترفيهية للمعلمين تعد منخفضة، لأن متوسط العبارة 9 بلغ 2.19، وتختلف النتيجة هذه مع نتيجة فطافطة (2018)، ونتير النتيجة الأخيرة الى عدم إيلاء المدراء المستهدفين الاهتمام للترفيه عن المعلمين، و عدم ادر اكهم لأهمية تنظيم النشاطات والرحلات التهية الترفيهية للمعلمين،

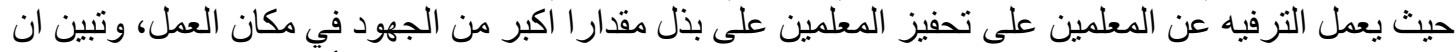

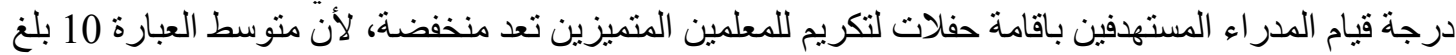
2.13، وتختلف النتيجة الاخيرة مع نتيجة المحرج أمداء (2020). تبين ان درجة قبام المدر اء المستهدفين بتشجيع المعلمين على القبام بمبادرات تعد مرتفعة، لأن متوسط العبارة 11 بلغ 4.69، وتتفق النتيجة الاخيرة مع نتيجة المحرج (2020)، وتنير النتيجة الأخيرة الى انى ان المدراء المستهدفين يحرصون على تشجيع المعلمين على اطلاق مبادرات تسهم في تقدم المجتمع وخدمة ابناءه، وتقوة وتهية

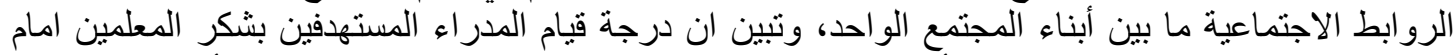

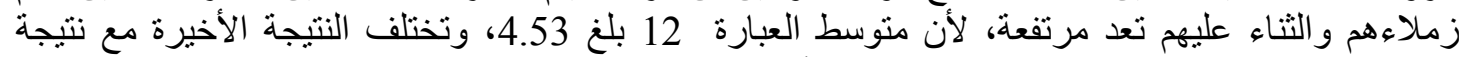
النعيمي (2015)، و هذا يشير الى وعي المدراء بأهمية اشعار المعلمين بالتقدير امام زملائهم لخلق جو منافسة

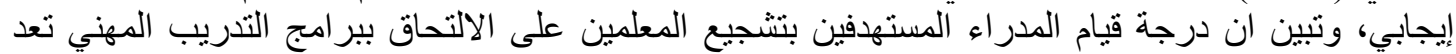

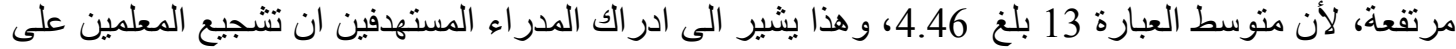
الالتحاق بهذه البرامج سيسهم في تطور هم مهنيا، وسينعكس ذلك ايجابا على تحقيق اهداف ورؤى الادارة

13. الخلاصة

لقد تبين ان درجة ممارسة مديري المدارس الأساسية في محافظة عجلون مهارة تحفيز المعلمين من وجهة نظر

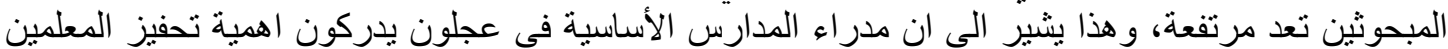

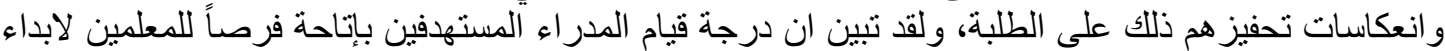

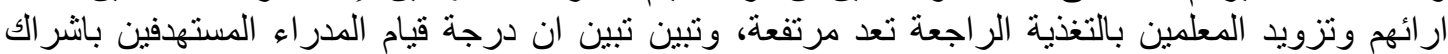

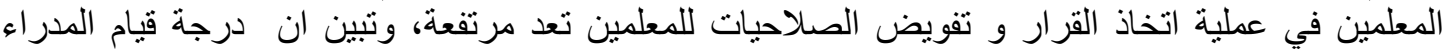

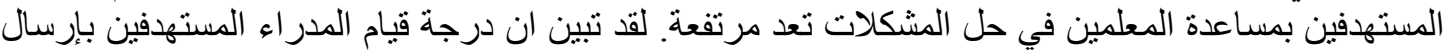
رسائل شكر للمعلمين المتميزين، وشكر المعلمين امام زملاءهم و الثناء تعد مرتفعة، وتبين تبين ان درجة درجة قيام

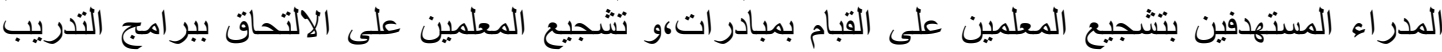

$$
\text { المهني تعد مرتفعة. }
$$

ولكن، لقد تبين ان درجة قيام المدر اء المستهدفين بتقييم المعلمين بشكل موضوعي تعد متوسطة. ولقد تبين ان

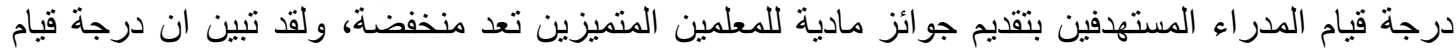
المدر اء المستهدفين بتنظيم رحلات ترفيهية للمعلمين تعد منخفضة،هودرجة قيام المدراء باقامة حفلات فئنة لتكريم

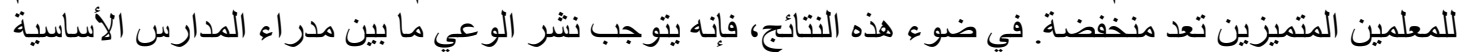

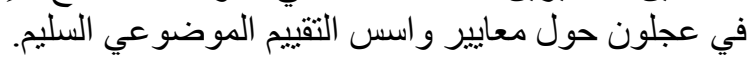

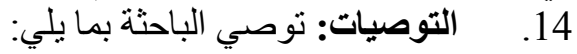
- ـ وضع خطط من قبل وزارة التربية و التعليم الأردنية لتحفيز المعلمين، و العمل على تطوير هذه الخطط بشكل

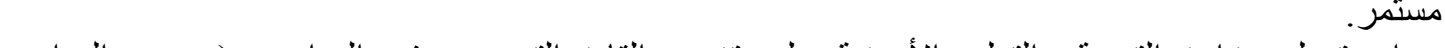
- ان تعمل وزارة التربية والتعليم الأردنية على تزويد القادة التربوبين في المدارس (مديري المدارس و المشرفين) بدورات تمعل على توعيتهم بأهمية تحفيز المعلمين، وتزويد بارية بالمهارات التي تمكنهم من تحفيز

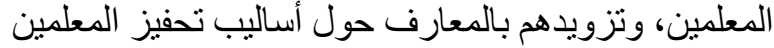
- عقد دور ات للتنمية المهنية للمعلمين من قبل وزارة التربية و المعلمين من اجل تطوير هم مهنياً. ان ذلك سيسهم تهين في تحفيز هم 


\begin{tabular}{|c|c|c|c|}
\hline 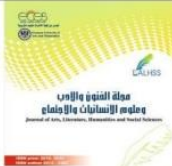 & 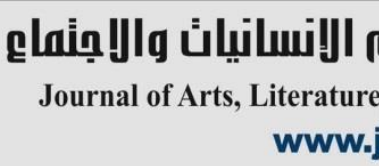 & 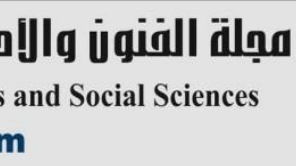 & \\
\hline$=\quad=$ & Volume (67) May 2021 & العدد (67) مايو 2021 & \\
\hline
\end{tabular}

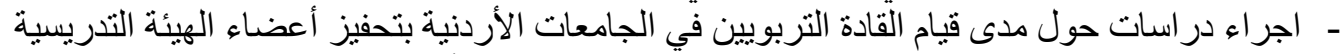

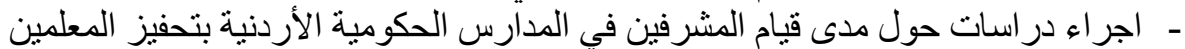
شكر وتقدير:

تود الباحثة شكر وزارة التربية والتعليم في الأردن، لتقديمها الدعم الدائم للمعلمين، ولاهتمامها بالطلبة بكافة

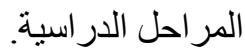

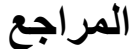

1. بن حميدة، عبد الله (2018). واقع التحفيز لاى المشرف التربوي في مرحلة التعليم الابتدائي. مجلة العلوم الاجتماعية والإنسانية. جامعة محمد بوضياف المسيلة، 7 (14).

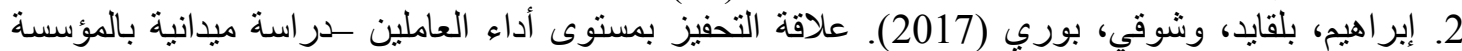

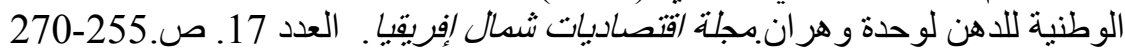

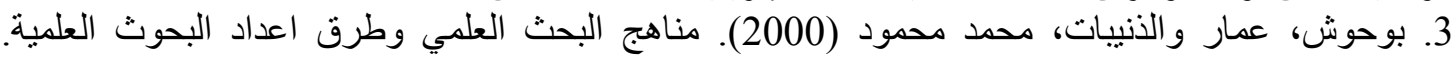
الجز ائر. ديو ان المطبو عات الجامعية. 4. أبو حميد، محمد (2020). أثر الحوافية الفز المادية والمعنوية على أداء العاملين. المجلة العربية للنشر العلدي.

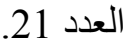

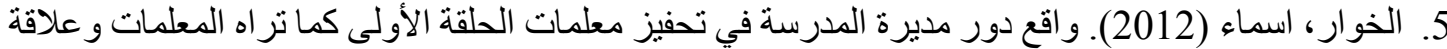

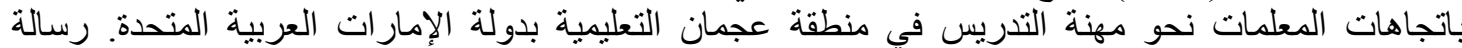
ماجستير منشورة. الامار ات. جامعة الامار التهات العات العربية المتحدة.

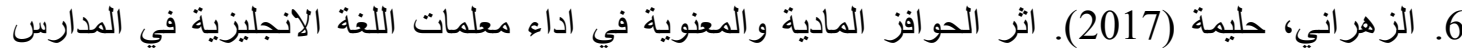

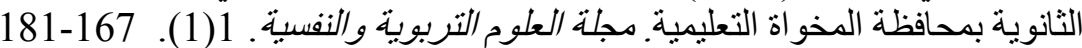

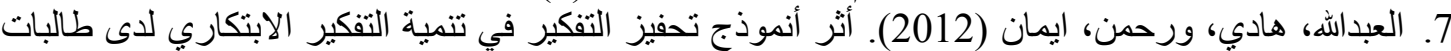

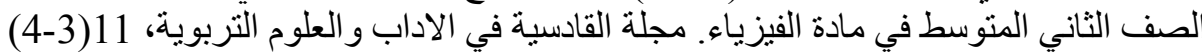

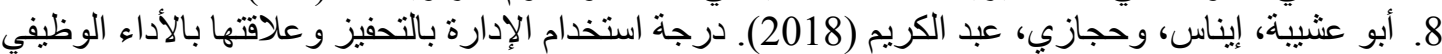

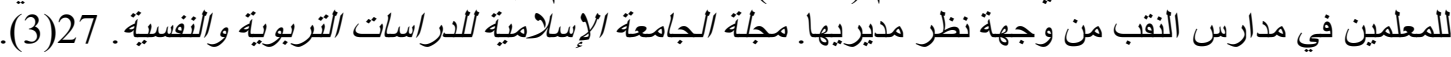
$.361-344$ 9. فطافطة، مجدولين (2019). أساليب التحفيز الممارسة من قبل مديري المدارس ودوربا في تحسين أداء

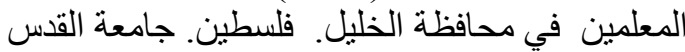
10. كامل، محمد المغربي (2004) السلوك التنظيمي مفاهيم و اسس سلوك الفرد و الجماعة في التنظيه. طبعة رقم

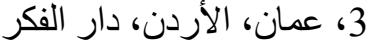
11. المحرج، عبد الكريم (2020).و اقع تحفيز مديري المدارس في مدينة الرياض للعاملين معهم. مجلة العلوم

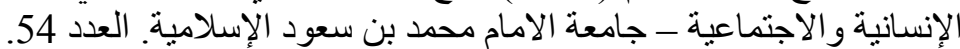
https://www.imamjournals.org/index.php/jshs/article/view/456 12 13. محمد، بوزيدي (2018). فاعلية استخدام إستراتيجية التحفيز في عملية الإشراف التربوي. الدجلة الدولية

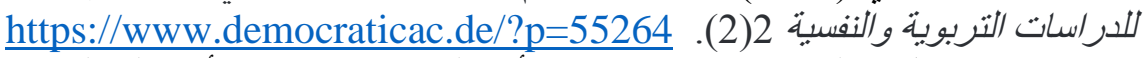

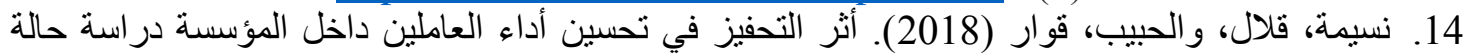
مؤسسة اتصالات الجز ائر. رسالة ماجستير منشورة. الجزائر. جامعة عبد الترائ الحميد بن باديس مستغانم http://search.shamaa.org/FullRecord?ID=120153.15

16. النعيمي، احمد (2015). دور مدير المدرسة في تحفيز معلمي مدارس الحلقة الثانية بمدينة العين. رسالة ماجستير منشورة. الامار ات. جامعة الامار ات العربية العاتية المتحدة.

17.Aljbour, H. (2020). The Extent of Practicing Ethical Leadership by Public Secondary School Principals in Amman. The Journal of Education and Practice. 11(15). 57-63, DOI: 10.7176/JEP/11-15-07.

18.Amin, M. (2018). Challenges Faced by Novice EFL Teachers. International Journal of Humanities and Cultural Studies. 5(1). 149-166 


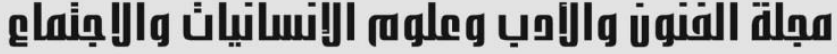 \\ Journal of Arts, Literature, Humanities and Social Sciences www.jalhss.com}

\section{Volume (67) May 2021}

العدد (67) مايو 2021

19.Belle, L. (2007). The role of secondary school principals in motivating teachers in the Flacq district of Mauritius. Published MA thesis. South Africa. University of South Africa

20.Han, J.; Yin, H.; and Boylan, M. (2016). Teacher motivation: Definition, research development and implications for teachers. Cogent Education, 3(1) https://doi.org/10.1080/2331186X.2016.1217819

21. Ofoegbu, F. (2004). Teacher motivation: A factor for classroom effectiveness and school improvement in Nigeria. College student journal, 38(1), 81-88.

22. Salehi, M., \& Farhang, A. (2019). On the adequacy of the experimental approach to construct validation: the case of advertising literacy. Heliyon, 5(5) https://doi.org/10.1016/j.heliyon.2019.e01686

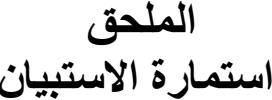

انا الباحثة جملا صالح جروان إسماعيل. إنني اعمل على جمع البيانات عبر الاستبيان الحالي من اجل الجان اجراء

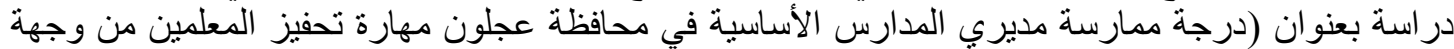

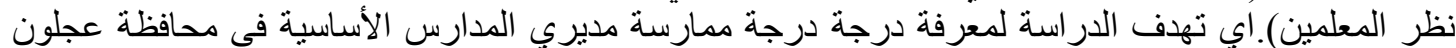

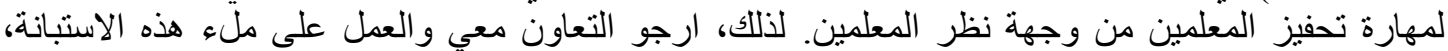

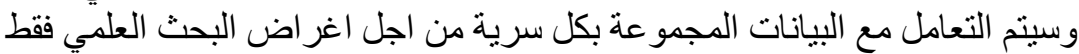

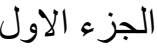

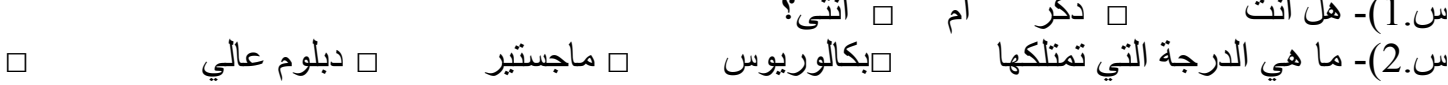
دكتور اه؟

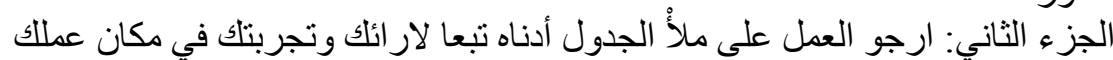

\begin{tabular}{|c|c|c|c|c|c|c|}
\hline 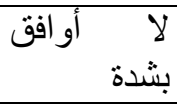 & 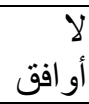 & 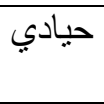 & 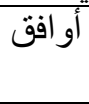 & 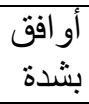 & 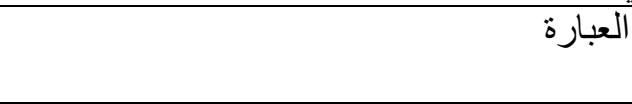 & 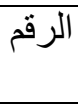 \\
\hline & & & & & ان مديري/مديرتي في المدرسة يعمل/تعمل على & \\
\hline & & & & & اتاحة الفرص لي لابداء ر ايي & .1 \\
\hline & & & & & تزويدي بالتغذية الر اجعة دائماً & .2 \\
\hline & & & & & اشر اكي في عملية اتخاذ القرار & .3 \\
\hline & & & & & تفويص عدداً من الصلاحيات لي & .4 \\
\hline & & & & & تقديم جوائز مادية للمعلمين المتميزين & .5 \\
\hline & & & & & مساعدة المعلمين في حل المشكلات & .6 \\
\hline & & & & & ارسال رسائل شكر للمعلمين المتميزين & .7 \\
\hline & & & & & تقييمي بشكل موضوعي & .8 \\
\hline & & & & & تنظيم رحلات ترفيهية للمعلمين & .9 \\
\hline & & & & & اقامة حفلات تكريم للمعلمين & .10 \\
\hline & & & & & تشجيعي على القبام بمبادر ات & .11 \\
\hline & & & & & عليهر المعلمين المتميزين امام زملانهم و الثناء & .12 \\
\hline & & & & & تشجيعي على الالتحاق ببر امج التدريب المهني & .13 \\
\hline
\end{tabular}

